\title{
Prior Performance and Risk-Taking of Mutual Fund Managers: A Dynamic Bayesian Network Approach
}

\author{
Manuel Ammann and Michael Verhofen* \\ October 2006 \\ forthcoming in the Journal of Behavioral Finance, 8(1), 2007
}

\begin{abstract}
We analyze the behavior of mutual fund managers with a special focus on the impact of prior performance. In contrast to previous studies, we do not solely focus on the volatility as a measure of risk, but also consider alternative definitions of risk and style. Using a Dynamic Bayesian Network, we are able to capture non-linear effects and to assign exact probabilities to the mutual fund managers' adjustment of behavior. In contrast to theoretical predictions and some existing studies, we find that prior performance has a positive impact on the choice of the risk level, i.e., successful fund managers take more risk in the following calendar year. In particular, they increase the volatility, the beta and the tracking error and assign a higher proportion of their portfolio to value stocks, small firms and momentum stocks. Overall, poor performing fund managers switch to passive strategies.
\end{abstract}

Keywords: Mutual Funds, Risk Taking, Dynamic Bayesian Network

JEL classification: G21

\footnotetext{
*Manuel Ammann (manuel.ammann@unisg.ch) is professor of finance at the Swiss Institute of Banking and Finance, University of St. Gallen, Switzerland, and Michael Verhofen (verhofen@gmail.com) is visiting scholar at the Haas School of Business, University of California at Berkeley. We thank the editor, Bernd Brommundt, Alexander Ising, Stephan Kessler, Axel Kind, Jennifer Noll, Angelika Noll, Ralf Seiz, Stephan Süss, Rico von Wyss, and Andreas Zingg for valuable comments. We acknowledge helpful comments of the participants from the Joint Research Workshop of the University of St. Gallen and the University of Ulm in 2005. We acknowledge financial support from the Swiss National Science Foundation (SNF).
} 


\section{Introduction}

The behavior of mutual fund managers has been subject to considerable academic research. As rational agents, they are supposed to adjust their behavior in consideration of the incentives they are facing. Basically, these incentives can be divided into two different aspects, the structure of compensation schemes and the behavior of investors. On the one hand, most compensation schemes are constructed like a call option, i.e., fund managers have a higher upside than downside potential. This provides a temptation for fund managers to increase the riskiness in a suboptimal way for the investor. On the other hand, in a multi-period context, a positive relation between past performance and new fund flows has been observed. A fund manager who has shown a high performance is rewarded with new capital. In contrast, a manager with a poor performance does not suffer from the same amount of cash outflows. If compensation is linked to fund size, this provides an incentive for increasing the riskiness of a portfolio to a suboptimal point from an investor's perspective. In short, in so called mutual fund tournaments portfolio managers compete for better performance, greater fund inflows, and higher compensation.

From a theoretical point of view, a number of authors focus on agency conflicts in the mutual fund industry, i.e., on asymmetric information and hidden action between mutual fund managers and their investors, and on the call option-like function of compensation schemes. Fund managers might unnecessarily shift the fund's risk in response to the fund's relative performance. This behavior is linked to compensation and investor's reaction. Carpenter (2000) solves the dynamic investment problem of a risk averse manager compensated using a call option on the assets he controls, i.e., a convex compensation scheme. She shows that under the manager's optimal policy, the option is likely to end up deep in or deep out of the money because managers take, in general, more risk than the 
investor would choose. Berk \& Green (2004) propose a model that incorporates two important features: First, performance is not persistent and, second, fund flows rationally respond to past performance. In particular, they assume that investors behave as Bayesians, i.e., they update their beliefs about a fund manager's skill based on observed returns and prior beliefs. They show that a rational model for active portfolio management when talent is a scarce resource disappearing as a fund grows can explain many empirical observations without relying on investors irrationality and asymmetric information. Similar models also relying on Bayesian updating have been proposed by Schmidt (2003) and Dangl, Wu \& Zechner (2004). Lynch \& Musto (2003) address the question how fund managers change their strategy over time. In their model, they show that strategy changes only occur after periods of poor performance.

From an empirical point of view, different authors have analyzed the actual behavior of mutual fund managers. Deli (2002) investigates marginal compensation rates in mutual fund advisory contracts. He finds that marginal compensation depends positively on turnover and the fund type (e.g. equity, closed-end), and is negatively related to fund size and size of the fund family. Therefore, incentives to take risk might differ across fund managers.

Chevalier \& Ellison (1997) estimate the shape of the relationship between performance and new fund flows because the shape of this relation creates incentives for fund managers to increase or decrease the riskiness of the fund. They find that funds tend to change their volatility depending on the relative performance by the end of September. Similarly, Brown, Harlow \& Starks (1996) focus on mid-year effects. In particular, they test the hypothesis that mutual managers showing an underperformance by mid year change the fund's risk differently than those mutual fund managers showing an outperformance at the 
same point in time. Their empirical analysis shows that mid-year losers tend to increase the fund's volatility to a greater extent than their successful counterparts. Busse (2001) suggests that some prior findings might be spurious. Using daily data and the methodology by Brown et al. (1996) he finds no mid-year effect. In sum, existing empirical analyses have failed to deliver clear evidence on the behavior of mutual fund managers and there are doubts about the robustness of the findings.

In this paper, we contribute to the existing empirical literature in a number of ways. In contrast to existing studies, we do not solely focus on volatility as a measure of risk. We take into account also other measures such as the beta and the tracking error, and style measures such as the high-minus-low (HML) factor, the small-minus-big (SMB) factor, and the momentum (UMD) factor. Furthermore, in contrast to previous studies, we use a robust, non-parametric approach. As we do not impose any distributional assumptions, we are able to capture a wide range of non-linear and asymmetric patterns. Moreover, instead of using a particular theoretical model describing the behavior of fund managers as a starting point, our study is designed in an explorative way. Concerning the data, we do not use only a sub-group of mutual funds, but a complete set of all US equity funds for a long time period of data.

In this paper, we compute conditional transition matrices and compare whether the conditional transition matrices are different for successful and unsuccessful mutual funds. For the empirical analysis, we use a Bayesian Network. A Bayesian Network is a model for representing conditional dependencies between a set of random variables. Up to now, research on Bayesian Networks (BN) is mainly concentrated in statistics and computer science, particularly, in artificial intelligence (Korb \& Nicholson (2004), Neapolitan (2004)), in pattern recognition (Duda, Hart \& Stork (2001)) and expert systems (Jensen 
(2001), Cowell, Dawid, Lauritzen \& Spiegelhalter (2003)). However, although the term "Bayesian Network" has not yet widely spread, special cases of Bayesian Networks are widely used in economics and finance. In particular, many state space models such as the Kalman filter and Hidden Markov models are Bayesian Networks with a simple dependency structure. Moreover, many classical econometric approaches such as discrete choice models and regressions are so-called Naive Bayesian Networks because of their mono-causal dependency structure (Jordan, Ghahramani \& Saul (1997)).

Bayesian Networks work as follows. Suppose there are three variables such as the tracking error in period $T$, the return in period $T$, and the tracking error in period $T+1$. Suppose next that all variables are conditionally dependent, i.e., the tracking error in period $T$ affects the return in period $T$ and the tracking error in period $T+1$. Moreover, also the return in period $T$ affects the tracking error in $T+1$. In classical econometrics, this problem is determined as multicollinearity and might lead to identification problems. Bayesian networks can deal with such complex settings and can help to overcome the identification problem. For a discussion of a wide range of different settings of Bayesian Networks, we refer to Pearl (2000).

Besides being a modern tool for identifying the impact of and magnitude of different causal sources, using Bayesian Networks has a number of advantages over standard econometric methods. For example, they allow the computation of exact conditional probabilities to assess the magnitude of a factor. For example, we can analyze whether the probabilities change from 50:50 to $60: 40$ or to $90: 10$ for a given evidence. Moreover, Bayesian Networks are able to capture non-linear and asymmetric patterns.

Using Bayesian Networks on a set of US equity funds over about 20 years of data, we find that prior performance has a positive impact on the choice of the risk level, i.e., successful 
fund managers take more risk in the following time period. In particular, they increase the volatility, the beta, and the tracking error and assign a higher proportional of their portfolio to value stocks, small firms and momentum stocks.

The article is structured as follows. In Section 2, we outline the econometric approach. In Section 3, we present our empirical results. Section 4 concludes.

\section{Model}

\subsection{Introduction to Bayesian Networks}

We start with a description of Bayesian Networks. For short, a Bayesian Network is a graphical model for representing conditional dependencies between a set of random variables. This includes, in particular, learning about conditional distributions and updating beliefs about probability distributions for a target node given some observation for at least one variable.

Figure 1 shows a Dynamic Bayesian Network. The structure is similar to the Bayesian Networks which have been proposed by Pearl (2000) for causal discovery. The circles denote the nodes, i.e., the variables in the Bayesian Network, and the arcs the conditional dependency between two nodes. The conditional dependency between two nodes can be basically of any type. The most frequently conditional probability distributions (CPD) used are Gaussian distributions and multinomial (or tabular) distributions. In the example in Figure 1 a binomial distribution is used.

We are using a Dynamic Bayesian Network to analyze the revision of behavior in the mutual fund industry. In particular, we analyze how past performance affects a set of 
variables which describe the risk taking behavior of mutual fund managers. Suppose a fund manager can, at least to some degree, choose the tracking error of his portfolio, i.e., how close he mimics the relevant index or whether he chooses a more active investing style. By assumption, there is a fifty-fifty chance that the portfolio manager chooses a high or low tracking error. Suppose next that the choice of the magnitude of the tracking error affects the subsequent return. In particular, a low tracking error leads to a chance of $50 \%$ of a high return and to $50 \%$ of a low return. In contrast, it is assumed, that a high tracking error leads to a chance of $90 \%$ of a low return and $10 \%$ of a high return.

The tracking error in period $T+1$ is an effect of two variables, the tracking error in period $T$ and the return in period $T$. These conditional dependencies have a straightforward interpretation. On the one hand, it might be that there is some degree of persistency in the behavior, i.e., a fund manager who has had a high tracking error in period $T$ tends to maintain a high tracking error. On the other hand, there might be some degree of learning or revision of behavior.

Figure 1 shows how the Dynamic Bayesian Network can be used to update beliefs about probability distributions. Suppose the investor knows that a fund had a superior performance in period $T$. The question of inference is how this knowledge affects the belief about the distribution of the tracking error in period $T+1$. As shown in Figure 1 , the straightforward application of Bayes theorem leads to a probability of $91.50 \%$ for a high tracking error and of $8.5 \%$ for a low tracking error.

Bayesian Networks are frequently also denoted as probabilistic networks (Cowell et al. (2003)), Bayesian Artificial Intelligence (Korb \& Nicholson (2004)) and Bayesian Belief Networks (Duda et al. (2001)). As noted by Borgelt \& Kruse (2002), Bayesian Networks 
rely on the achievements of a number of other concepts and in particular on classification and regression trees, naive Bayes classifiers, artificial neural networks and graph theory. A number of other econometric approaches such as the Kalman Filter, Hidden Markov Models and state space models in general can be regarded as special cases of Bayesian Networks and, in particular, of Dynamic Bayesian Networks (DBN), as shown by Jordan et al. (1997). Even regressions and discrete choice models can be incorporated in a Bayesian Network structure such as in so-called Naive Bayes Nets. Bayesian Networks (BN) are a very powerful tool to deal with uncertainty, incomplete information and complex probabilistic structures. In particular, Bayesian Networks enable the extraction of probabilistic structures from data and decision making in these structures. Therefore, Bayesian Networks are well-suited for financial applications.

In this section, we address the three main issues associated with Bayesian Networks. First, the question of representation, i.e., what is a Bayesian Network. Second, the question of learning (estimation) of parameters of a Bayesian Network. Third, the question of inference, i.e., how Bayesian Networks can be used to answer probabilistic questions. For an extended coverage of the topic and for a coverage of decision making within Bayesian Networks, we refer to Jensen (2001), Cowell et al. (2003), Korb \& Nicholson (2004) and Neapolitan (2004).

\subsection{Representation}

As defined by Jensen (2001), a Bayesian Network consists of a set of variables with directed arcs between these variables. These variables form a directed acyclic graph (DAG) and, for each arc that connects two variables, a potential table, i.e., a conditional distribution, is defined. 
Suppose there are four random variables, $A, B, C$, and $D$. Applying the chain rule, the joint probability can be written as a product of conditional probabilities $P(A, B, C, D)=P(D \mid A, B, C) \cdot P(C \mid A, B) \cdot P(B \mid A) \cdot P(A)$. Suppose next, $A$ and $D$ are conditionally independent, i.e., $P(A, D \mid B, C)=P(A \mid B, C) \cdot P(D \mid B, C)$ and $B$ and $C$ are conditionally independent. Using Bayes theorem and the previous factorization, it can be shown that

$$
\begin{aligned}
P(A, D \mid B, C) & =\frac{P(A, B, C, D)}{P(B, C)} \\
& =\frac{P(A) \cdot P(B) \cdot P(C \mid A) \cdot P(D \mid B, C)}{\iint P(A) \cdot P(B) \cdot P(C \mid A) \cdot P(D \mid B, C) d A d D} .
\end{aligned}
$$

Basically, three elementary theorems of probability, i.e., Bayes theorem, the chain rule, and conditional dependency, are the building blocks for Bayesian Networks.

\subsection{Learning}

In the previous subsection, we assumed that the parameters, i.e., the conditional probability distributions, are known. However, in most cases it is necessary to learn about the parameters of a Bayesian Network based on a data set. For parameter learning, maximum likelihood (ML) can be used. As noted by Ghahramani (2001), the likelihood decouples into local terms involving each node and its parents. This simplifies the maximum likelihood estimation because it reduces to number of local maximization problems.

Suppose a data set consists of $M$ cases for each of the $n$ nodes. Let $d^{(h)}=\left(d_{1}^{(h)}, \ldots, d_{n}^{(h)}\right)^{\prime}$ denote the vector of observations for a single case for all nodes in the network. Therefore, the training data set $d$ is given $d=\left\{d^{(1)}, d^{(2)}, \ldots, d^{(M)}\right\}$. Neapolitan (2004) shows that the likelihood function is given by 


$$
L(d \mid \theta)=\prod_{i=1}^{n} \prod_{h=1}^{M} P\left(d_{i}^{(h)} \mid p a_{i}^{(h)}, \theta_{i}\right)
$$

where $p a_{i}^{(h)}$ contains the values of the parents of the node $X_{i}$ in the $h$ th case and $\theta$ the parameter set.

In this paper, we use a multinomial distribution. In this case, the maximization problem simplifies to a closed-form solution if the data are complete. Then, the likelihood function is given by

$$
L(d)=\prod_{i=1}^{n} \prod_{j=1}^{q_{i}} E\left(\prod_{k=1}^{r_{i j}} F_{i j k}^{s_{i j k}}\right),
$$

where $q_{i}$ denotes the parents of node $X_{i}$ and $r_{i}$ the number of different classes of the multinomial distribution. $F_{i j k}$ denotes the distribution of node $i$ conditional on the parent node $j$ where the value of node $x_{i}$ is equal to $k$. The exponent $s_{i j k}$ denotes the number of cases in which $x_{i}$ is equal to $k$. The proof of these results can be found in Neapolitan (2004). Suppose next the conditional distributions $F_{i j k}$ have a Dirichlet distribution, i.e., a generalized Beta distribution, with (prior) parameters $a_{i j 1}, a_{i j 2}, \ldots, a_{i j r_{i}}, N_{i j}=\sum_{k} a_{i j k}$ and $M_{i j}=\sum_{k} s_{i j k}$. Then, the likelihood is given by

$$
L(d)=\prod_{i=1}^{n} \prod_{j=1}^{q_{i}} \frac{\Gamma\left(N_{i j}\right)}{\Gamma\left(N_{i j}+M_{i j}\right)} \prod_{k=1}^{r_{i}} \frac{\Gamma\left(a_{i j k}+s_{i j k}\right)}{\Gamma\left(a_{i j k}\right)}
$$

where $\Gamma($.$) denotes the gamma function. The use of Dirichlet distributions as conditional$ distribution has a couple of advantages and is not restrictive at all. The Dirichlet distribution is the so called natural conjugate prior for the multinomial distribution, i.e., an application of Bayes theorem with the Dirichlet distribution as prior distribution and the multinomial distribution as likelihood leads to a closed form solution for the posterior distribution which has the same functional form as the prior, i.e., a Dirichlet distribution. 
Therefore, the Dirichlet distribution is very helpful for Bayesian sequential analysis and Bayesian updating. Moreover, the Dirichlet distribution has upper and lower bounds and is therefore very helpful for modelling probabilities that cannot become greater than 1 or lower than 0. Concerning prior information, we can incorporate prior information about conditional dependencies or assign almost uninformative priors by setting all $a_{i j k}$ to 1 .

\subsection{Inference}

Suppose, the structure of a Bayesian Network and all conditional probability distributions (CPD) are known and a researcher has evidence about at least one node for a new case. The goal of probabilistic inference (also belief updating, belief propagation or marginalization) is to update the marginal probabilities in the network to incorporate this new evidence (Ghahramani (2001)). Formally, the task of inference is to find the posterior distribution $P(X=x \mid E=e)$, where $X$ denotes the query node and $E$ the set of evidence nodes.

By using the local structure of a Bayesian Network, it can be shown that belief updating can be divided into the predictive support for $X$ from evidence nodes connected to $X$ through its parents, $U_{1}, \ldots, U_{m}$, and the diagnostic support for $X$ from evidence nodes connected to $X$ through its children, $Y_{1}, \ldots, Y_{m}$ (Korb \& Nicholson (2004)). Pearl’s message passing algorithm (Pearl (1982)) shows how to update the posterior distribution $\operatorname{Bel}(X)$. The derivation involves the repeated application of Bayes Theorem and the use of the conditional independencies encoded in the network structure. The basic idea is that, at each iteration of the algorithm, $\operatorname{Bel}(X)$ is updated locally using three parameters, $\lambda(X), \pi(X)$ and the conditional probability table (CPT), where $\lambda(X)$ and $\pi(X)$ are computed using the messages received from the parents $\pi$ and from the children $\lambda$ of node $X$ (Korb \& 
Nicholson (2004)). In Bayes Theorem, $\pi$ plays the role of the prior and $\lambda$ the role of the likelihood.

The algorithm requires three types of parameters to be maintained. First, the current strength of the predictive support $\pi$ contributed by each incoming link $U_{i} \rightarrow X$, i.e., $\pi_{X}\left(U_{i}\right)=P\left(U_{i} \mid E_{U_{i} \backslash X}\right)$, where $E_{U_{i} \backslash X}$ is all evidence connected to $U_{i}$ except via $X$. Second, the current strength of the diagnostic support $\lambda$ contributed by each outgoing link $X \rightarrow Y_{j}: \lambda_{Y_{j}}(X)=P\left(E_{Y_{j} \backslash X} \mid X\right)$ where $E_{Y_{j} \backslash X}$ is all evidence connected to $Y_{j}$ through its parents except via $X$. Third, the fixed conditional probability distribution (CPD) $P\left(X \mid U_{i}, \ldots, U_{n}\right)$, i.e., the conditional distribution of node $X$ is only dependent on its parents.

Pearl's message-passing algorithm consists of two steps. In the first step, i.e., belief updating, messages arriving from the parents or the children of an activated node $X$ and lead to changes in belief parameters. In the second step, i.e., bottom-up and top-down propagation, the activated node computes new messages for the parents $\lambda$ and for the children $\lambda$ to send it into the appropriate direction.

In the first step, the posterior distribution of each activated node $X$ proportional to the messages from the parents $\pi_{X}\left(U_{i}\right)$ and to the messages from its children $\lambda_{Y_{j}}(X)$ is determined as follows

$$
\operatorname{Bel}\left(x_{i}\right)=\alpha \lambda\left(x_{i}\right) \pi\left(x_{i}\right)
$$

where $\pi\left(x_{i}\right)=\sum_{u_{1}, \ldots, u_{n}} P\left(x_{i} \mid u_{1}, \ldots, u_{n}\right) \prod_{i} \pi_{X}\left(u_{i}\right)$ and 


$$
\lambda\left(x_{i}\right)=\left\{\begin{array}{l}
1 \text { if evidence is } X=x_{i} \\
0 \text { if evidence is for another } x_{j} \\
\prod_{j} \lambda_{Y_{j}}\left(x_{i}\right) \text { otherwise }
\end{array}\right.
$$

and where $\alpha$ is a normalizing constant rendering $\sum_{x_{i}} \operatorname{Bel}\left(X=x_{i}\right)=1$.

In the second step, the bottom-up and top-down propagation step, node $X$ sends new $\lambda$ messages to its parents

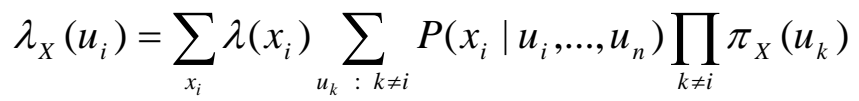

and the new $\pi$ messages to its children

$$
\pi_{Y_{j}}\left(x_{i}\right)=\left\{\begin{array}{l}
1 \text { if evidence value } x_{i} \text { is entered } \\
0 \text { if evidence is for another value } x_{j} \\
\alpha \operatorname{Bel}\left(x_{i}\right) / \lambda_{Y_{j}}\left(x_{i}\right) \text { otherwise }
\end{array}\right.
$$

This procedure is repeated until a node has received all messages.

Inference methods can be distinguished into two main categories, exact inference and approximate inference algorithms. The latter have been developed because probabilistic inference can be a computationally hard problem for complex networks with a large number of nodes because required computational power increases exponentially with the number of parent nodes. Well-known algorithms for exact inference include variable elimination, Pearl's message-passing algorithm, the noisy-or-gate algorithm, and the junction tree algorithm. For approximate inference, standard algorithms include likelihood weighting, logic sampling and Markov Chain Monte Carlo (MCMC) (for an overview, see Korb \& Nicholson (2004) or Neapolitan (2004)).

\subsection{Data}


For the analysis, we use a complete sample about all US open-end equity funds containing 1923 funds. The data set has been provided by Reuters Lipper. For each single fund, information about the fund's launch date, the fund's sector (Equity, International, Large Cap, Mid Cap, and Small Cap), its style (Income, Core, Growth, Value), its annual fee and its total assets per April, 30th, 2004, are available. Price information is available on a monthly basis for 19 years, i.e., from December 1984 to December 2003. For the analysis, we exclude international mutual funds and funds with less than two years of data. For benchmarking purposes, we use the excess return on S\&P 500 index as the market portfolio and the 3-month Treasury bill rate as the risk-free rate. The data are from Datastream. As a second benchmark, the Carhart (1997) four-factor model is used. The data for the market risk premium, the size premium, the value premium and for the momentum premium, are from the Fama and French data library.

Table 1 shows the descriptive statistics for the data used in this study. The number of funds increased from 191 in year 1985 to 1478 in the year 2003. The average return across all funds fluctuated substantially during that time with a minimum of $-26.35 \%$ in 2002 and a maximum of $28.26 \%$ in 2003. Similarly, the performance of single funds shows a high degree of dispersion.

\subsection{Performance Measurement}

To measure a fund's performance, a number of different approaches have been suggested (e.g. Kothari \& Warner (2001), Wermers (2000), Daniel, Grinblatt, Titman \& Wermers (1997)). To estimate the exposure towards the Fama \& French (1993) risk factors and the Carhart (1997) momentum factor, we run the following regression for each fund $i$ and for each calendar year $t$ : 


$$
\begin{aligned}
r_{i, t}-r_{f, t}= & \alpha_{\text {Carhart }, i, t}+M R P_{\text {Carhart }, i, t} \cdot r_{\text {Carhart }}+H M L_{i, t} \cdot r_{H M L}+ \\
& S M B_{i, t} \cdot r_{S M B}+U M D_{i, t} \cdot r_{U M D}+\varepsilon_{\text {Carhart }, i, t}
\end{aligned}
$$

where $r_{i, t}$ denotes the return of a fund $i, r_{f, t}$ the risk-free rate and $\varepsilon_{\text {Carhart,i,t }}$ the regression residual. The coefficients to be estimated are denoted by $M R P_{\text {Carhart,i,t, }} H M L_{i, t}, S M B_{i, t}$ and $U M D_{i, t}$, and risk premia by $r_{C a r h a r t}, r_{H M L}, r_{S M B}$ and $r_{U M D}$. An analogous approach is used for the risk exposure with respect to the S\&P 500, i.e.,

$$
r_{i, t}-r_{f, t}=\alpha_{S P 500, i, t}+M R P_{S P 500, i, t} \cdot r_{S P 500}+\varepsilon_{S P 500, i, t}
$$

In the following analysis, we refer to $R_{\text {Raw }, i, t}=r_{i, t}$ as the unadjusted return of a fund, to $R_{S P 500, i, t}=\alpha_{S P 500, i, t}$ as the risk-adjusted return using the S\&P 500 as benchmark, and to $R_{\text {Carhart }, i, t}=\alpha_{\text {Carhart, }, \text { t, }}$ as the risk-adjusted return using the Carhart four-factor model as benchmark.

The tracking error measures a fund's deviation from a passive index. We define the tracking error $T E$ as the volatility $\sigma$ of the residuals of the regressions on the index, i.e.,

$$
T E_{\text {Carhart }, i, t}=\sigma\left(\varepsilon_{\text {Carhart }, i, t}\right) \text { and } T E_{S P 500, i, t}=\sigma\left(\varepsilon_{S P 500, i, t}\right) \text {. }
$$

\subsection{Implementation}

Figure 2 shows the corresponding Dynamic Bayesian Network. For each fund, we estimate for each year eight different factors describing the behavior of a mutual fund. In particular, we use the standard deviation of returns, the beta against the S\&P 500 and the Fama and French market portfolio, the loading on the value vs. growth factor, the loading on the size factor, the loading on the momentum factor, and the tracking error against the S\&P 500 and the Fama and French market portfolio. 
A likelihood ratio test was performed and showed that all arcs in the Bayesian Network are highly significant.

To get robust results that are independent of restrictive distributional assumptions and to incorporate non-linear behavior, we use a multinomial distribution with four classes where variables are grouped into quartiles for each year.

The implementation of the Bayesian Network has been carried out using the "Bayes Net Toolbox for MatLab”. For testing, we created a large number of different artificial data sets and re-extracted the underlying probability distributions. In all instances, the underlying probability distributions were recovered accurately.

The Bayesian Network has been initialized by setting all $a_{i j k}$ to 1 . Therefore, the analysis incorporates no material prior information. The Bayesian Network is primarily used as an econometric tool.

\section{Empirical Results}

The analysis is structured as follows. We first focus on the marginal distributions within a time period that is the relation between risk and return. Then, we focus on intertemporal relations of different measures of risk and style. Finally, we turn to the marginal distributions of risk and style conditional on past performance.

Due to the large amount of empirical results, we focus in the empirical part on riskadjusted returns using the S\&P 500 as benchmark in a one-factor model. If not stated otherwise, results for unadjusted returns and returns adjusted with the Carhart four-factor model are very similar.

\subsection{Risk and Return}


Table 2 shows the relation between the set of variables describing the risk exposure of mutual funds and the following performance measured on a risk-adjusted basis. Significance has been tested against a null hypotheses of no probabilistic relation, i.e., the null hypothesis for a multinomial distribution with four classes is that the probability for each class is $25 \%$.

Table 2 is interpreted as follows. Suppose a fund has in one particular year a volatility in the lowest quartile among all other funds. Then, the fund has a probability of $11.8 \%$ (first row, first column) to achieve a risk-adjusted return in the lowest quartile among all other funds. Analogously, the chance is $30.8 \%$ (first row, fourth column) to obtain a riskadjusted return in the highest quartile among all other funds.

We find that the higher the volatility, the more likely a fund has an extreme return in quartile 1 (Q1) and quartile 4 (Q4). The transition probability of ending in the first quartile of returns is only $11.8 \%$ for funds with a volatility in Q1 and $22.8 \%$ for funds with a volatility in Q4. Similarly, funds with a low standard deviation in Q1 have a chance of 30.8\% of reaching a high return in Q4 whereas funds with a high standard deviation in Q4 have a chance of $41.4 \%$. Consequently, funds with a low risk level have a higher chance of reaching a return centered around the mean. For example, a fund with a volatility in Q1 has a chance for a return in Q2 of $28.9 \%$ whereas a fund with a high volatility fund has a chance of $16.6 \%$.

For the exposure to the market risk, i.e., the beta, the finding is reversed. Funds with a low beta in Q1 have a chance of $42.6 \%$ of achieving a risk-adjusted return in Q4. High-beta funds have only a transition probability to a return in Q4 of 33.0\%. The data show that the higher a fund's beta is, the lower is its relative risk-adjusted return. 
The style factors in the Carhart (1997) four-factor model, i.e., the value premium, the size premium and the momentum premium (UMD), show the expected results. As documented by Fama \& French (1993), trading strategies based on size factors and valuation ratios have historically earned superior returns. Value oriented funds, i.e., funds with a high loading on the value premium (HMLT in Q4) had a chance for a return in Q4 of 44.2\%. In contrast, growth funds (HMLT in Q1) had a chance for a return in Q4 of 32.6\%. Similarly, small-caps funds, i.e., funds with SMBT in Q4, had a chance for a return in Q4 of 44.4\%, while for large cap stocks this value was only $24.2 \%$. Even more evident is this findings for momentum funds. Funds with a high exposure to momentum stocks (Q4) had a 49.4\% chance for a return in the highest quartile. Vice versa, for funds avoiding momentum stocks (Q1), this chance is reduced to $17.0 \%$.

The tracking error indicates the magnitude of active portfolio management of a fund manager. The transition matrix shows that fund managers with a high tracking error (Q4) are with $45.8 \%$ more likely of having a return in the highest quartile than fund managers with a low tracking error (Q1) having a chance of 25.\%. The data indicate that active portfolio management has had some value.

\subsection{Persistence in Risk Levels}

In this section, we analyze the persistence in the choice of risk levels. Table 3 shows the relation between a measure of risk, e.g., the standard deviation, in period $T$ and the successive period $T+1$. Of special interest are the diagonal elements of the transition matrix because they represent the degree of persistence in the choice of risk levels.

For the standard deviation the probabilities of staying in the same quartile, i.e., the diagonal elements of the transition matrix, are 50.4\%, 37.8\%, $41.2 \%, 70.1 \%$, respectively. 
This means that a fund with a low return volatility has a chance of $50.4 \%$ of staying in the lowest quartile, a fund with a volatility in the second quartile of $37.8 \%$ of staying in the same quartile, and so on. In contrast, for the exposure towards market risk, the data show a lower degree of persistence in behavior. For the beta against the S\&P 500 only $46.0 \%$, $31.0 \%, 36.4 \%, 54.1 \%$, respectively, stay in the same class. Therefore, we conclude that the fund managers change their market risk to a larger extent than the portfolio's volatility and, in general, the degree of persistence is larger for funds with a very low or a very high exposure to a risk factor.

Similar are the findings for the style factors in the Carhart (1997) four-factor model. While for the HML factor, the transition probabilities for staying in the same class are $49.7 \%$. 34.4\%, 32.4\%, 44.4\%, the transition probabilities for the SMB factor are $49.03 \%$, 33.1\%, 35.1\%, 68.7\%. For the momentum (UMD) factor, the transition probabilities are $42.9 \%$, 32.7\%, 31.3\%, 46.9\%. Therefore, over the whole sample, the persistence in the choice of risk levels is particularly high for fund investing to a large extent in small caps (high SMB factor). However, this finding is consistent with prior expectations because the choice of risk level and its persistence is, at least partially, induced by a fund's policy.

For the tracking error against the S\&P 500, the diagonal transition probabilities are $61.9 \%$, $36.8 \%, 32.5 \%, 62.4 \%$. Therefore, the persistence of active and passive portfolio management measured as the deviation from the index is substantial.

Overall, we find strong evidence for persistence in the choice of risk levels. In particular, funds with a very high and very low exposure to specific risk factors show a high degree of persistence. However, these results are not surprising because a number of factors and, in particular, institutional restrictions induce a persistent behavior. 


\subsection{The Impact of Prior Performance}

In this section, we turn to the impact of prior performance on the risk taking of mutual fund managers. The complete empirical results are included in the appendix in Tables A1 and A2. Due to the large amount of empirical data, we focus the interpretation on the results shown in the Tables 4 and 5.

Table 4 shows the difference in transition probabilities for top- and poor-performing mutual funds for risk-adjusted returns using the S\&P 500 as benchmark index. For the volatility, we find that fund managers with a poor performance, in general, strongly decrease their portfolio volatility in the following calendar year. For example, the difference in transition probabilities for funds with a volatility in the highest quartile is 18.9\%. Only successful funds with a low volatility (in Q1) increase the volatility in the following calendar year.

For the beta, the evidence is mixed. Funds with an exposure to the market risk above the median (Q3 and Q4) take more market risk in the following calendar year, e.g. the difference in transition probabilities for Q4 to Q4 is 9.8\%. This indicates that successful fund managers are $9.8 \%$ more likely to maintain their risk level than for unsuccessful managers. In contrast, unsuccessful managers with a beta in Q1 increase their market risk exposure significantly. For example, the difference in transition probabilities from Q1 to Q2 is $-8.4 \%$. This indicates than poor-performing funds are $8.4 \%$ more likely to increase their market risk exposure.

The style factors are interpreted as follows. A high loading (e.g. in Q4) on the value factor (HML) indicates that a fund invests in value stocks. Vice versa, a low factor loading on the value factor (Q1) is interpreted as an investment in growth stocks. A fund investing in 
small caps shows a high exposure to the size factor (SMB) and a large-cap funds shows an exposure to in the first quartile. Funds investing in momentum stocks have a high loading on the UMD factor (Q4) and contrarian funds a low loading on UMD.

For the HML, SMB and UMD factor, there is overwhelming evidence for increased risk taking by successful fund managers. Successful fund managers invest in the future heavily in value stocks, small caps and momentum stocks.

For the loading on the value premium (HML), all differences in transition probabilities ending in Q1 are negative and ending in Q4 are positive. For example, successful funds having invested in growth stocks are $6.7 \%$ more likely to switch to a substantial value investment (transition element Q1 to Q4) and poor-performing funds are 8.5\% more likely to continue the unsuccessful growth stock investments (transition element Q1 to Q1).

For the size exposure, the change in behavior is even stronger. All successful manager regardless of their prior size exposure invest substantially in small caps. For example, successful managers who have previously invested primarily in large caps are $6.8 \%$ more likely to invest substantially in small caps than their unsuccessful counterparts (transition probability Q1 to Q4).

For the momentum exposure, the previously observed pattern, i.e., increased risk-taking by successful mangers, is also observable, but less evident. Material changes are observable for fund managers having previously neglected momentum stocks (Q1). If these fund managers achieved a good-performance they are 9.5\% more likely to invest in the future heavily in momentum stocks than poor-performing managers (transition probability Q1 to Q4).

The tracking error as a measure of active portfolio management validates the findings for other variables. Successful managers increase, in general, the tracking error and poor- 
performing fund managers tend to decrease it. For example, successful fund managers are 17.0\% more likely to maintain a tracking error in the highest quartile (Q4) compared to unsuccessful fund managers.

Next, we analyze how portfolio managers respond to prior performance measured with the Carhart four-factor model. As shown by Carhart (1997), the four-factor model explains a high proportion of the cross sectional variance of the performance of mutual funds. After accounting for a fund's exposure against value and growth stocks, large and small caps, and momentum stocks, he finds little evidence for persistence in the performance of mutual funds.

Overall, a comparison of the results for returns risk-adjusted with the Carhart four-factor model on the one side and with a one factor model, i.e. the S\&P 500 as benchmark indicate differences as shown in Table 5 . While Table 4 indicates substantial and significant changes in behaveor, in particular for the first and fourth quartiles, the results for the Carhart four-factor model are less evident.

For the volatility, we find, in general, no significant evidence for a change in behavior. However, there is little evidence for increased risk-taking by low performing funds. For the Beta, the data confirm our previous findings. A good performance induces increased taking of market risk in the following period. However, most findings are statistically insignificant.

For the HML, SMB and UMD factor, the results differ somehow from previous findings and are mixed. For HML, we find clear statistically significant pattern. For SMB findings reverse. For UMD, results are ambiguous. For the Carhart four-factor, we find strong evidence that successful fund managers abstain from small caps. For example, the 
transition probability from Q4 to Q4 is -3.4\%. This indicates that successful fund managers tend to reduce their exposure to small caps compared to poor-performing fund managers. After controlling for a fund's style, we find that unsuccessful funds tend to change their momentum strategy into different directions. For example, the transition probability Q2 to Q2 is significantly positive, having a value of $8.1 \%$. This indicates that successful funds are $8.1 \%$ more likely to choose a comparable momentum level. Unsuccessful funds change their strategy into both directions, a contrarian strategy and a stronger momentum strategy. For the tracking error, superior performance induces a more passive investments style after controlling for a fund's style. However, this findings is only significant for the first quartile transition probabilities.

\subsection{Discussion}

In this section, we discuss the results of our econometric analysis with respect to theoretical models and with respect to other empirical findings.

Existing literature trying to explain the behavior of mutual fund managers (e.g., Brown et al. (1996), Chevalier \& Ellison (1997), Carpenter (2000), Busse (2001), and Carhart, Kaniel, Musto \& Reed (2002)) has focussed on incentives faced by mutual fund managers. Incentives in the mutual fund industry are primarily driven by two factors, by the compensation schemes and the behavior of investors. Standard compensation schemes in the mutual fund industry are convex, i.e., fund managers take part in the positive performance of their funds by receiving bonuses while they usually do not take part in the negative performance of their funds. Portfolio managers have a call option on the portfolio they are managing. Moreover, as a second important incentive factor, the intertemporal behavior of investors increases the effect of convex compensation schemes. Investors 
allocate a large proportion of new capital to funds with a high performance in the previous period whereas they do not withdraw invested capital from poorly performing funds. Therefore, if a manager's salary depends on the assets under management, investors' behavior induces a convex relation between fund performance and fund size. Overall, both patterns lead in theory to excessive risk taking by mutual fund managers.

However, in our empirical analysis, we were unable to find evidence for such a behavior. In general, these findings can be explained by a different setting in this study compared to other empirical studies. In particular, we use a large sample of funds over a longer time period and different measures of risk and return. Moreover, we impose less restrictive assumptions for the empirical analysis, e.g., we do not assume any linear relation or a normal distribution. In particular, Brown et al. (1996) solely focus on volatility as a measure of risk and only use a rather small sample of funds, funds focussing on growth stocks, over a time period of 15 years. Their analysis focusses on mid-year effects and they find that funds performing poorly by mid-year increase their volatility for the rest of the year. Busse (2001) uses a very similar methodology and the same data set as in Brown et al. (1996), but with a daily frequency, and finds that the fund's intra-year change is attributable to changes in the volatility of common stocks and not related to changing factor exposures or residual risk. Similar, Chevalier \& Ellison (1997) analyze the impact of past performance on fund flows using a semi-parametric approach. Their results confirm prior expectations, i.e., the flow-performance relation creates incentives for fund managers to adjust the riskiness of the fund depending on mid-year performance.

How can we explain increased risk taking after years of good performance and decreased risk taking after years of poor performance? Our explanation is two-sided. First, poorperforming managers follow a more passive strategy to minimize the risk of their own 
future replacement. Relative performance and not absolute performance is relevant. Second, successful managers take more risk, because they have become more confident in their own skills. Success creates confidence. Basically, our analysis shows that a combination of the models by Lynch \& Musto (2003) for unsuccessful managers and Berk \& Green (2004) for successful managers describe the data best.

Lynch \& Musto (2003) propose a model in which strategy changes only occur after periods of bad performance. However, a priori, their model does not say how the strategy changes. In their empirical analysis, they find evidence for a change of factor loadings. They find that poor performers seem to increase their UMD loading and decrease their HML loading. Neither market beta nor SMB loading is systematically affected by fund performance. The different results by Lynch \& Musto (2003) in comparison to our analysis might be due to the shorter sample period in the analysis by Lynch \& Musto (2003) and to the use of a nonlinear model in our analysis. Our analysis shows that, after a period of bad performance, managers choose a passive investments style (lower tracking error), take less market risk, decrease their exposure to value, and increase their exposure to large caps, and stocks with a low momentum effect.

Berk \& Green (2004) propose a model that incorporates two important features. First, performance is not persistent, i.e., active portfolio managers do not outperform passive benchmarks on average and, second, funds flows rationally respond to past performance. In particular, they assume that investors behave as Bayesians, i.e., they update their beliefs about a fund manager's skill based on observed returns and prior beliefs. The same argumentation can be applied to a manager's belief about his own skills. Starting with some prior confidence on his own skills, he learns about his skills and uses his skills in the following time period. If skills require specific trading strategies, e.g., a fund manager has 
special skills in selecting small caps or value stocks, an empirical analysis will show patterns as we have observed.

Mutual fund managers behavior is more complex than assumed by theoretical models, which usually capture only one aspect of the actual behavior. According to our analysis, a combination of the models by Lynch \& Musto (2003) and Berk \& Green (2004) describes the findings best.

\section{Conclusion}

How do mutual fund managers react to past performance? Theory suggests that goodperforming mutual fund managers reduce their risk level and poor-performing managers take more risk because they do not bear the downside risk. However, such a behavior might be unrealistic in actual life due to restrictions fund managers are facing, such as tracking error restrictions. Moreover, other factors affecting the behavior of mutual fund managers might be more important than pure compensation maximization. For example, if relative performance is more important than absolute performance, they tend to take only little idiosyncratic risk compared to their relevant benchmark.

In this paper, we analyze a large sample of US investments funds for a period of 20 years. For each year, we compute different measures of style and risk. Overall, our analysis extends the existing literature in a number of ways. In contrast to existing studies, we do not solely focus on volatility as a measure of risk. We take also other measures such as the beta and the tracking error, and style measures such as the high-minus-low (HML) factor, the small-minus-big (SMB) factor, and the momentum (UMD) factor into account. Furthermore, we use a robust, non-parametric approach and are therefore able to capture a 
wide range of non-linear and asymmetric patterns because we do not impose any restrictive distributional assumptions. Concerning the data basis, we do not use only a sub-group of mutual funds, but a complete set of all US equity funds with a long time period of data.

Our analysis does not lend any support for the hypothesis that poor-performing fund managers increase the risk level. We find that prior performance has a positive impact on the choice of the risk level, i.e., successful fund managers take more risk in the following time period. In particular, they increase the volatility, the beta and the tracking error and assign a higher proportion of their portfolio to value stocks, small firms and momentum stocks. Overall, poor performing fund managers switch to passive strategies. Unsuccessful managers decrease the level of idiosyncratic risk and follow the relevant benchmark more closely.

\section{References}

Berk, J. \& Green, R. (2004), 'Mutual fund flows and performance in rational markets', Journal of Political Economy 112, 1269-1295.

Borgelt, C. \& Kruse, R. (2002), Graphical Models, John Wiley \& Sons, New York.

Brown, K., Harlow, W. \& Starks, L. (1996), 'Of tournaments and temptations: An analysis of managerial incentives in the mutual fund industry’, Journal of Finance 51, 85-110.

Busse, J. (2001), 'Another look at mutual fund tournaments', Journal of Financial and Quantitative Analysis 36, 53-73.

Carhart, M. (1997), 'On persistence in mutual fund performance', Journal of Finance 52, 57-82.

Carhart, M. M., Kaniel, R., Musto, D. K. \& Reed, A. V. (2002), 'Learning for the tape: Evidence of gaming behavior in equity mutual funds', Journal of Finance 68, 661-693.

Carpenter, J. (2000), 'Does option compensation increase managerial risk appetite?', Journal of Finance 55, 2311-2331. 
Chevalier, J. \& Ellison, G. (1997), 'Risk taking by mutual funds as a response to incentives’, Journal of Political Economy 105, 1167-1200.

Cowell, R. G., Dawid, A. P., Lauritzen, S. L. \& Spiegelhalter, D. J. (2003), Probabilistic Networks and Expert Systems, Springer, New York.

Dangl, T., Wu, Y. \& Zechner, J. (2004), 'Mutual fund flows and optimal manager replacement', Working Paper. University of Vienna.

Daniel, K., Grinblatt, M., Titman, S. \& Wermers, R. (1997), 'Measuing mutual fund performance with characteristic-based benchmarks', Journal of Finance 52, 1035-1058.

Deli, D. N. (2002), 'Mutual fund advisory contracts: An empirical investigation', Journal of Finance 57, 109-133.

Duda, R. O., Hart, P. E. \& Stork, D. G. (2001), Pattern Classification, John Wiley \& Sons, New York.

Fama, E. \& French, K. (1993), 'Common risk factors in the returns on stocks and bonds', Journal of Financial Economics 33, 3-57.

Ghahramani, Z. (2001), 'An introduction to Hidden Markov Models and Bayesian networks', International Journal of Pattern Recognition and Artificial Intelligence 15, 942.

Jensen, F. J. (2001), Bayesian Networks and Decision Graphs, Springer, New York.

Jordan, M. I., Ghahramani, Z. \& Saul, L. K. (1997), 'An introduction to variational methods for graphical models’, Working Paper .

Korb, K. B. \& Nicholson, A. E. (2004), Bayesian Artifical Intelligence, Chapmann \& Hall / CRC, New York.

Kothari, S. \& Warner, J. B. (2001), 'Evaluating mutual fund performance', Journal of Finance 56, 1985-2010.

Lynch, A. \& Musto, D. (2003), 'How investors interpret past fund returns', Journal of Finance 58, 2033-2058.

Neapolitan, R. E. (2004), Learning Bayesian Networks, Prentice Hall, Upper Saddle River.

Pearl, J. (1982), Reverend Bayes on inference engine: A distributed hierarchical approach, in 'Proceedings, Cognitive Science Society', Ablex, Greenwich, CT, pp. 329-334.

Pearl, J. (2000), Causality: Models, Reasoning and Inference, Cambridge University Press, Cambridge. 
Schmidt, B. (2003), 'Hierarchical Bayesian models, holding propensity and the mutual fund flow-performance relation’, Working Paper. University of Chicago.

Wermers, R. (2000), 'Mututal fund performance: An empirical decomposition into stockpicking, style, transactions costs, and expenses’, Journal of Finance 55, 1655-1695. 


\section{Exhibits}

\section{Figure 1}

\section{Illustration of a Dynamic Bayesian Network}

The three main issues in the area of Bayesian Networks are (1) the question of representation, i.e., what is a Bayesian Network, (2) probabilistic inference, i.e., the updating of probability distributions for a query node given evidence for a particular node, and (3) the estimation of parameters for conditional probability distributions for a Bayesian Network based on sample data.

Representation: A Bayesian Network consists of a set of variables, usually denoted as nodes (illustrated as circles). The arcs represent conditional dependencies in the network between nodes. Inference: Probabilistic inference denotes the updating of probability distributions for a query node given some evidence (posterior distribution). The Graph illustrates the probability updating for the query node $T R_{T}$, i.e., the tracking error in Period $T+1$, conditional on the evidence that $R_{T}$, i.e., return in period $T$, was high.

Learning: To learn the parameters for conditional probability distributions in a Bayesian Network maximum likelihood methods are applicable.

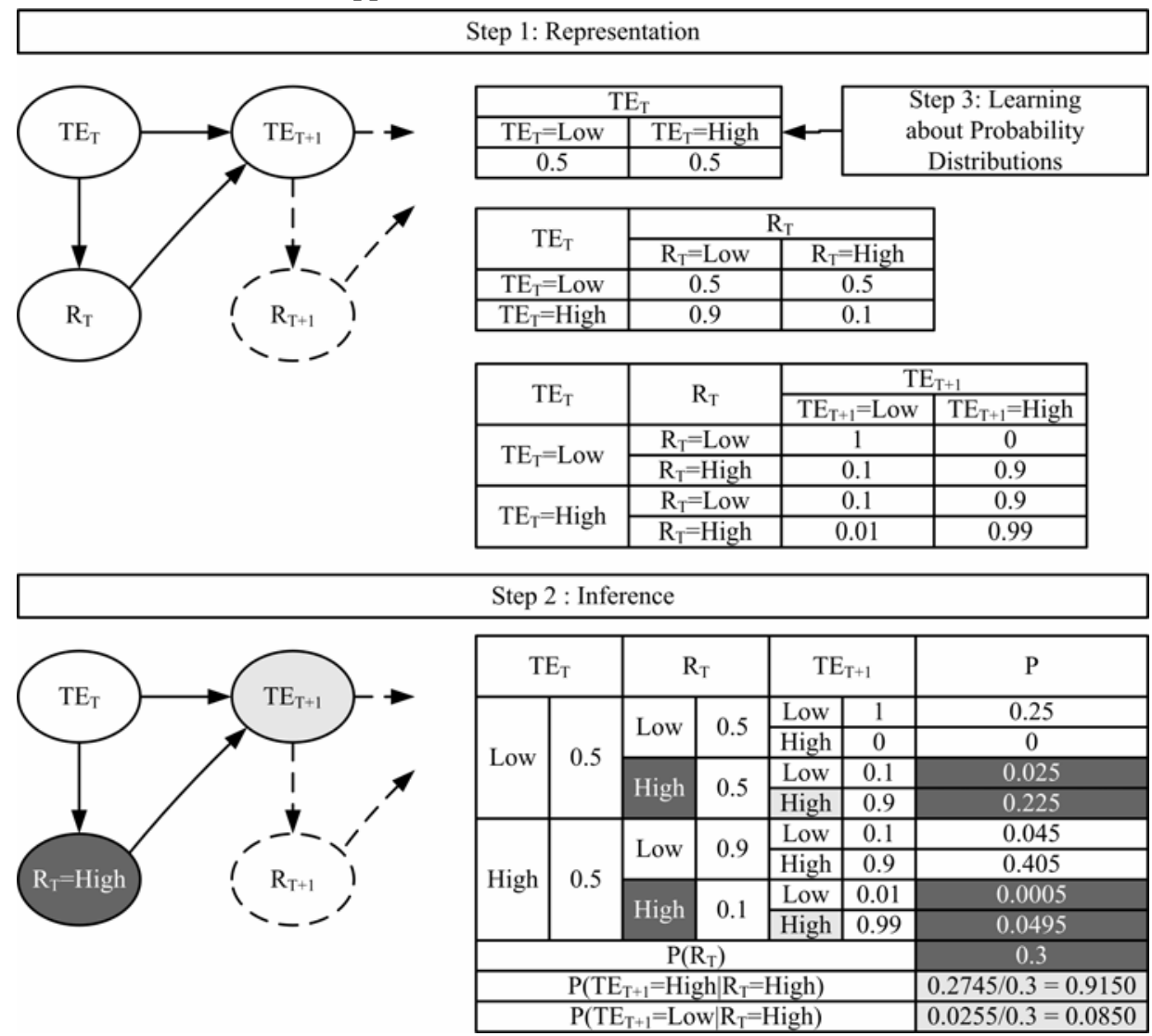


Figure 2

Dynamic Bayesian Network used in the empirical analysis

For a number of different measures of risk, we analyze the joint effect of the risk level in $T$ and the risk-adjusted return in $T$ on the choice of the risk level in $T+1$. The data set was provided by Reuters Lipper and consists of 1923 funds with return data from 1984 to 2004. As measures of risk we used: volatility $(S T D)$, the beta with respect to the market portfolio $(M R P)$, the factor loading on the value premium $(H M L)$, the factor loading on the size premium $(S M B)$, the factor loading on the momentum premium (UMD), and the tracking error (TE). A return is denoted by $R$. The tracking error and the beta have been computed with respect to the S\&P 500 and the CRSP market portfolio using a one factor and a four-factor model, respectively (denoted as $T E_{S P 500}, T E_{\text {Carhart }}, M R P_{S P 500}, M R P_{\text {Carhart }}$. Similar, return $R$ has been computed on a raw basis (without risk-adjustment), risk-adjusted in a one factor model with respect to the S\&P 500 and to the Carhart (1997) four factor model (denoted as $R_{\text {Raw }}, R S_{P 500}$, and $R_{\text {Carhart }}$ ).

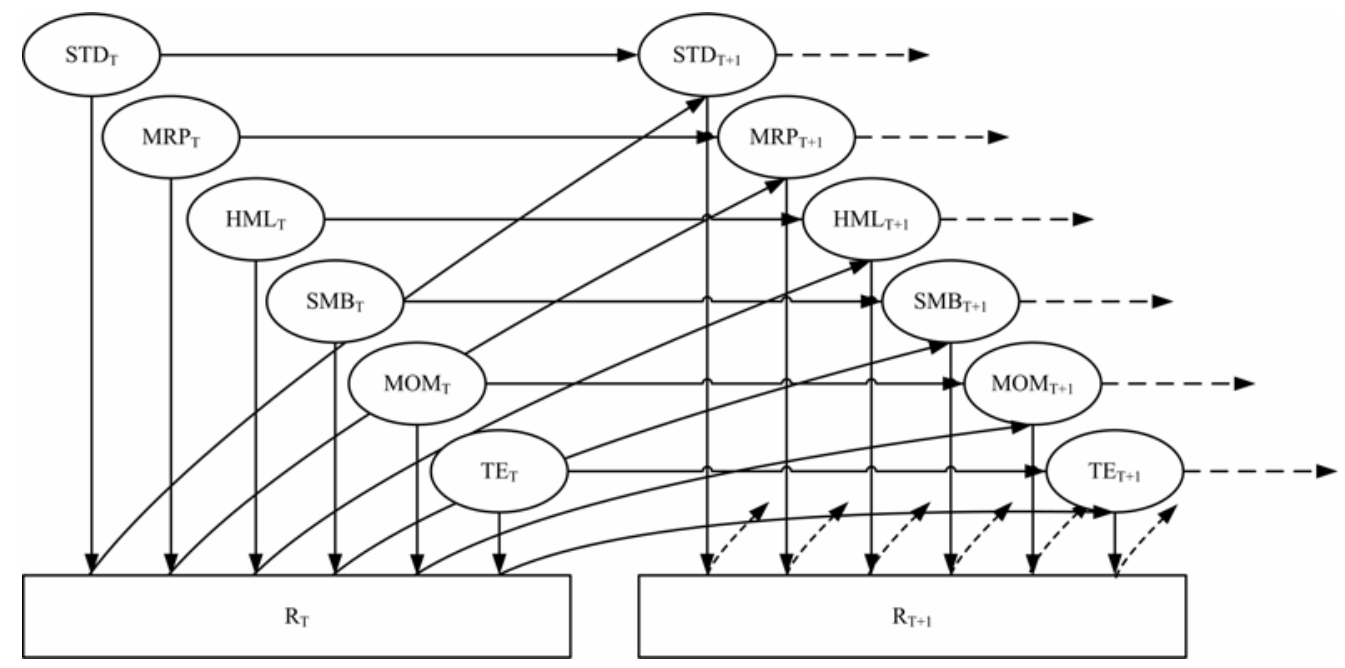


Table 1

Descriptive statistics for annual continuously compounded returns

The table shows the descriptive statistics for annual continuously compounded returns for all funds existing in one particular year. The data set is from Reuters Lipper.

\begin{tabular}{ccccccccccc}
\hline Year & Funds & Mean & Std. & Skew & Kurt & Min & $25 \%$ & $50 \%$ & $75 \%$ & Max \\
\hline 1985 & 191 & 18.87 & 7.37 & -0.01 & 3.67 & -3.23 & 14.18 & 19.43 & 23.23 & 43.56 \\
1986 & 216 & 0.49 & 10.80 & -0.20 & 5.28 & -48.43 & -5.64 & 0.55 & 8.00 & 45.38 \\
1987 & 243 & -13.49 & 12.46 & -0.23 & 5.87 & -60.19 & -19.86 & -13.13 & -5.38 & 42.81 \\
1988 & 284 & 9.46 & 8.12 & 0.08 & 4.52 & -15.31 & 4.27 & 9.58 & 14.36 & 46.10 \\
1989 & 305 & 15.31 & 8.38 & 0.01 & 3.44 & -9.40 & 10.36 & 14.95 & 20.95 & 41.45 \\
1990 & 326 & -11.70 & 8.79 & -0.63 & 3.76 & -41.48 & -16.63 & -10.80 & -5.52 & 11.51 \\
1991 & 350 & 26.28 & 12.08 & -1.29 & 16.97 & -75.62 & 18.99 & 25.39 & 32.88 & 63.08 \\
1992 & 387 & 3.52 & 8.02 & -0.72 & 7.93 & -48.47 & -0.39 & 3.59 & 7.29 & 30.10 \\
1993 & 452 & 5.34 & 8.53 & -1.14 & 10.06 & -51.79 & 0.49 & 5.73 & 10.44 & 36.90 \\
1994 & 539 & -6.52 & 7.30 & -0.54 & 5.32 & -41.25 & -10.34 & -5.95 & -2.41 & 21.08 \\
1995 & 622 & 20.44 & 8.72 & -0.36 & 5.07 & -22.82 & 15.67 & 21.01 & 25.75 & 48.42 \\
1996 & 701 & 9.39 & 9.09 & -1.07 & 9.59 & -61.24 & 4.93 & 9.56 & 14.72 & 44.06 \\
1997 & 822 & 11.36 & 11.24 & -1.18 & 7.27 & -56.69 & 5.48 & 12.89 & 18.44 & 49.91 \\
1998 & 977 & 6.57 & 15.34 & -0.12 & 3.58 & -48.04 & -3.24 & 6.84 & 16.87 & 58.22 \\
1999 & 1114 & 17.05 & 22.76 & 1.07 & 5.02 & -53.06 & 1.48 & 13.49 & 27.79 & 136.39 \\
2000 & 1233 & -12.14 & 22.51 & -1.52 & 9.89 & -188.63 & -23.45 & -10.09 & 2.68 & 40.86 \\
2001 & 1369 & -11.83 & 16.82 & -0.30 & 4.28 & -90.89 & -21.35 & -12.61 & -1.30 & 45.78 \\
2002 & 1478 & -26.35 & 11.34 & -0.66 & 5.64 & -103.74 & -32.59 & -26.08 & -19.18 & 14.08 \\
2003 & 1478 & 28.26 & 8.98 & 0.42 & 12.28 & -58.39 & 22.29 & 26.70 & 33.06 & 97.56 \\
\hline
\end{tabular}


Table 2

Transition probabilities between risk and return

The table shows the transition probabilities between different measures of risk and the subsequent return. * denotes a value statistically different from 0.25 on a $95 \%$ level and ** on a $99 \%$ level. Standard errors have been computed by bootstrapping.

The table is interpreted as follows. Suppose a fund has in one particular year a volatility in the lowest quartile among all other funds. Then, the fund has a probability of $11.8 \%$ (first row, first column) to achieve a risk-adjusted return in the lowest quartile among all other funds. Analogously, the chance is $30.8 \%$ (first row, fourth column) to obtain a risk-adjusted return in the highest quartile among all other funds.

\begin{tabular}{|c|c|c|c|c|c|}
\hline \multirow[b]{2}{*}{ from } & \multirow[t]{2}{*}{ to } & \multicolumn{4}{|c|}{$\mathrm{R}_{\mathrm{SP} 500, \mathrm{~T}}$} \\
\hline & & Q1 & Q2 & Q3 & Q4 \\
\hline \multirow[t]{4}{*}{$\mathrm{STD}_{\mathrm{T}}$} & Q1 & $11.8 \% *$ & $28.9 \%$ ** & $28.3 \%$ ** & $30.8 \%$ ** \\
\hline & Q2 & $15.5 \%$ * & $25.1 \%$ & $30.6 \%$ ** & $28.6 \%$ ** \\
\hline & Q3 & $17.9 \%$ * & $21.7 \%$ * & $25.0 \%$ & $34.4 \%$ ** \\
\hline & Q4 & $22.8 \%$ * & $16.6 \%$ * & $19.0 \%$ * & $41.4 \%$ ** \\
\hline \multirow[t]{4}{*}{$\mathrm{MRP}_{\mathrm{SP} 500, \mathrm{~T}}$} & Q1 & $16.0 \% *$ & $18.6 \% *$ & $22.6 \%{ }^{\star}$ & $42.6 \%$ *夫 \\
\hline & Q2 & $15.1 \%$ * & $22.4 \%$ * & $27.8 \%$ * & $34.5 \%$ ** \\
\hline & Q3 & $16.5 \%$ * & $25.7 \%$ & $27.4 \%$ ** & $30.2 \%$ ** \\
\hline & Q4 & $21.1 \%$ * & $21.8 \%$ * & $23.9 \%$ & $33.0 \%$ ** \\
\hline \multirow[t]{4}{*}{$\mathrm{HML}_{\mathrm{T}}$} & Q1 & $24.0 \%$ & $23.0 \% *$ & $19.4 \% *$ & $32.6 \%$ ** \\
\hline & Q2 & $15.7 \%$ * & $28.0 \%$ ** & $30.0 \%$ ** & $26.2 \%$ \\
\hline & Q3 & $13.1 \%$ * & $24.7 \%$ & $30.3 \%$ ** & $31.8 \%$ ** \\
\hline & Q4 & $17.8 \%$ * & $15.6 \%$ * & $22.2 \%$ * & $44.2 \%$ ** \\
\hline \multirow[t]{4}{*}{$\mathrm{SMB}_{\mathrm{T}}$} & Q1 & $21.7 \% *$ & $28.2 \%$ ** & $25.7 \%$ & $24.2 \%$ \\
\hline & Q2 & $14.5 \%$ * & $30.4 \%$ ** & $29.9 \%$ ** & $25.0 \%$ \\
\hline & Q3 & $13.3 \%$ * & $24.2 \%$ & $29.6 \%$ ** & $32.7 \%$ ** \\
\hline & Q4 & $19.5 \%$ * & $14.8 \%$ * & $21.1 \%$ * & $44.4 \%$ ** \\
\hline \multirow[t]{4}{*}{$\mathrm{UMD}_{\mathrm{T}}$} & Q1 & $33.7 \%$ ** & $30.7 \%$ ** & $18.4 \% *$ & $17.0 \%{ }^{*}$ \\
\hline & Q2 & $20.3 \% *$ & $32.1 \%$ ** & $26.5 \%$ ** & $21.0 \%{ }^{*}$ \\
\hline & Q3 & $12.9 \% *$ & $22.0 \%$ * & $32.0 \%$ ** & $33.0 \%$ ** \\
\hline & Q4 & $12.9 \%$ * & $14.3 \%$ * & $23.2 \%$ * & $49.4 \%$ ** \\
\hline \multirow[t]{4}{*}{$\mathrm{TE}_{\mathrm{SP} 500, \mathrm{~T}}$} & Q1 & $14.3 \% *$ & $29.2 \%$ ** & $30.8 \%$ ** & $25.5 \%$ \\
\hline & Q2 & $18.1 \%$ * & $25.1 \%$ & $27.7 \%$ ** & $29.0 \%$ ** \\
\hline & Q3 & $18.0 \%$ * & $19.0 \%$ * & $22.5 \%$ * & $40.3 \%$ ** \\
\hline & Q4 & $20.7 \%$ * & $13.9 \%$ * & $19.4 \%$ * & $45.8 \%$ ** \\
\hline
\end{tabular}


Table 3

\section{Transition probabilities between risk in $T$ and $T+1$}

The table shows the transition probabilities between different measures of risk in $T$ and $T+1$. XXX denotes that the target (column) variable is the same variable as in the appropriate row. The table shows the results for the model with risk-adjustment using the S\&P 500. * denotes a value statistically different from 0.25 on a $95 \%$ level and $* *$ on a 99\% level. Standard errors have been computed by bootstrapping.

The table is interpreted as follows. Suppose a fund has in one particular year a volatility in the lowest quartile among all other funds. Then, the fund manger has selected with a probability of $50.4 \%$ (first row, first column) a return volatility in the lowest quartile among all funds in the next calendar year. Analogously, the chance is $2.6 \%$ (first row, fourth column) to select a volatility on the highest quartile among all other funds in the next calendar year.

\begin{tabular}{|c|c|c|c|c|c|}
\hline \multirow[b]{2}{*}{ from } & \multirow[t]{2}{*}{ to } & \multicolumn{4}{|c|}{$\begin{array}{c}\mathrm{XXX}_{\mathrm{T}} \\
\mathrm{M}: \mathrm{R}_{\mathrm{SP} 500, \mathrm{~T}}\end{array}$} \\
\hline & & Q1 & Q2 & Q3 & Q4 \\
\hline \multirow[t]{4}{*}{$\mathrm{STD}_{\mathrm{T}}$} & Q1 & $50.4 \%$ ** & $32.9 \%$ ** & $14.0 \% *$ & $2.6 \% *$ \\
\hline & Q2 & $24.4 \%$ & $37.8 \% \%^{\star \star}$ & $29.7 \%^{\star \star}$ & $7.9 \%$ * \\
\hline & Q3 & $8.4 \% *$ & $22.8 \%$ & $41.2 \% \%^{\star \star}$ & $27.4 \%$ \\
\hline & Q4 & $1.2 \% *$ & $6.3 \%{ }^{*}$ & $22.2 \%{ }^{*}$ & $70.1 \%$ ** \\
\hline \multirow[t]{4}{*}{$\mathrm{MRP}_{\mathrm{SP} 500, \mathrm{~T}}$} & Q1 & $46.0 \%$ ** & $28.7 \%$ ** & $17.6 \% *$ & $7.5 \%^{*}$ \\
\hline & Q2 & $25.4 \%$ & $31.0 \%$ ** & $27.9 \%$ ** & $15.5 \%$ * \\
\hline & Q3 & $11.8 \% *$ & $25.5 \%$ & $36.4 \%$ ** & $26.1 \%$ \\
\hline & Q4 & $4.7 \%^{*}$ & $13.8 \%$ * & $27.0 \%$ & $54.1 \%$ ** \\
\hline \multirow[t]{4}{*}{$\mathrm{HML}_{\mathrm{T}}$} & Q1 & $49.7 \%$ ** & $24.6 \%$ & $15.5 \% *$ & $9.9 \%^{*}$ \\
\hline & Q2 & $26.4 \%$ & $34.3 \%$ ** & $25.0 \%$ & $13.3 \%$ * \\
\hline & Q3 & $14.9 \% *$ & $27.7 \%$ ** & $32.4 \%$ ** & $24.8 \%$ \\
\hline & Q4 & $11.5 \%$ * & $15.4 \%$ * & $28.5 \% \%^{\star \star}$ & $44.4 \%$ ** \\
\hline \multirow[t]{4}{*}{$\mathrm{SMB}_{\mathrm{T}}$} & Q1 & $49.3 \%$ ** & $29.5 \%$ ** & $14.7 \% *$ & $6.4 \% *$ \\
\hline & Q2 & $37.8 \%$ ** & $33.1 \%$ ** & $18.9 \% *$ & $10.0 \%$ * \\
\hline & Q3 & $15.4 \% *$ & $17.7 \%{ }^{*}$ & $35.1 \%{ }^{\star \star}$ & $31.7 \%$ ** \\
\hline & Q4 & $4.2 \%{ }^{*}$ & $5.8 \% \%^{*}$ & $21.1 \%{ }^{*}$ & $68.7 \%$ ** \\
\hline \multirow[t]{4}{*}{$\mathrm{UMD}_{\mathrm{T}}$} & Q1 & $42.9 \%{ }^{\star \star}$ & $25.2 \%$ & $18.0 \% *$ & $13.7 \% *$ \\
\hline & Q2 & $26.0 \%$ & $32.7 \%$ ** & $24.5 \%$ & $16.1 \%$ * \\
\hline & Q3 & $16.1 \% *$ & $27.8 \%$ ** & $31.3 \%$ ** & $24.6 \%$ \\
\hline & Q4 & $11.4 \%$ * & $15.2 \%$ * & $26.3 \%$ & $46.9 \%$ ** \\
\hline \multirow[t]{4}{*}{$T E_{S P 500, T}$} & Q1 & $61.9 \%$ ** & $25.5 \%$ & $9.1 \%{ }^{*}$ & $3.4 \% \%^{*}$ \\
\hline & Q2 & $22.5 \%$ & $36.8 \%$ ** & $25.4 \%$ & $15.2 \% *$ \\
\hline & Q3 & $7.4 \% *$ & $23.9 \%$ & $32.5 \%$ *夫 & $36.0 \%$ ** \\
\hline & Q4 & $1.7 \%^{*}$ & $9.8 \%{ }^{*}$ & $26.0 \%$ & $62.4 \%$ ** \\
\hline
\end{tabular}


Table 4

Impact of prior performance on the choice of risk level (returns adjusted with the S\&P 500)

The table shows the difference in transition probabilities between different measures of risk in $T$ and $T+1$ for funds with a performance in the highest quarter in $T$ and for funds with a performance in the lowest quarter in $T$. XXX denotes that the target (column) variable is the same variable as in the appropriate row. The table shows the results for returns adjusted with the S\&P 500. * denotes a value statistically different from 0 on a $95 \%$ level and $* *$ on a $99 \%$ level. Standard errors have been computed by bootstrapping. The results displayed in this table base on a risk-adjusted return using a one factor model and the S\&P 500 as market portfolio.

The results in the table have been computed as follows. Top-performing funds are funds with a return in the fourth quartile in one calendar year, poor-performing funds are funds with a return in the first quartile in one calendar year. Both groups have different transition matrices for the risk level in the next year. In this table, we show the difference of element-by-element subtraction of the transition matrices. The transition matrix of poor-performing funds has been subtracted from the matrix of top-performing funds. Therefore, positive elements indicate that the transition probability for top-performing funds was higher than for poor-performing funds and vice-versa.

\begin{tabular}{|c|c|c|c|c|c|}
\hline \multirow[b]{2}{*}{ from } & \multirow[t]{2}{*}{ to } & \multicolumn{4}{|c|}{$\begin{array}{c}\mathrm{XXX}_{\mathrm{T}+1} \\
\text { Difference }\end{array}$} \\
\hline & & Q1 & Q2 & Q3 & Q4 \\
\hline \multirow[t]{4}{*}{$\mathrm{STD}_{\mathrm{T}}$} & Q1 & $6.3 \%$ & $-1.5 \%$ & $-1.1 \%$ & $-3.6 \% \%^{\star \star}$ \\
\hline & Q2 & $-10.3 \%$ ** & $-0.9 \%$ & $7.4 \% *$ & $3.8 \%$ * \\
\hline & Q3 & $-8.5 \%$ ** & $-9.0 \%$ ** & $0.0 \%$ & $17.0 \%$ *ᄎ \\
\hline & Q4 & $-2.1 \%$ ** & $-6.0 \%$ ** & $-10.7 \%$ ** & $18.9 \%$ ** \\
\hline \multirow[t]{4}{*}{$\mathrm{MRP}_{\mathrm{SP} 500, \mathrm{~T}}$} & Q1 & $13.3 \%$ ** & $-8.4 \%$ ** & $-1.8 \%$ & $-3.0 \%$ ** \\
\hline & Q2 & $3.3 \%$ & $-6.8 \% \%^{\star \star}$ & $3.3 \%$ & $0.0 \%$ \\
\hline & Q3 & $-5.8 \% \%^{\star \star}$ & $-4.7 \%^{\star \star}$ & $1.7 \%$ & $8.8 \% \%^{\star \star}$ \\
\hline & Q4 & $-5.0 \%$ ** & $-1.8 \%$ & $-3.0 \%$ & $9.8 \%$ ** \\
\hline \multirow[t]{4}{*}{$\mathrm{HML}_{\mathrm{T}}$} & Q1 & $-8.5 \%$ ** & $-3.6 \%$ & $5.4 \%^{\star \star}$ & $6.7 \%$ ** \\
\hline & Q2 & $-8.4 \%$ ** & $-0.5 \%$ & $2.3 \%$ & $6.6 \%$ ** \\
\hline & Q3 & $-7.1 \%^{\star *}$ & $-4.1 \%$ & $5.8 \% *$ & $5.4 \% *$ \\
\hline & Q4 & $-9.8 \%^{\star \star}$ & $-0.5 \%$ & $3.2 \% *$ & $7.1 \%^{\star \star}$ \\
\hline \multirow[t]{4}{*}{$\mathrm{SMB}_{\mathrm{T}}$} & Q1 & $-6.7 \% *$ & $-3.1 \%$ & $3.0 \%$ & $6.8 \%^{\star \star}$ \\
\hline & Q2 & $-11.4 \%$ ** & $-1.8 \%$ & $5.5 \% *$ & $7.7 \%$ ** \\
\hline & Q3 & $-13.1 \%$ ** & $-7.9 \%$ ** & $5.0 \% *$ & $16.0 \%$ *^ \\
\hline & Q4 & $-6.5 \%^{\star \star}$ & $-5.8 \% \%^{\star \star}$ & $-1.2 \%$ & $13.6 \%$ *^ \\
\hline \multirow[t]{4}{*}{$\mathrm{UMD}_{\mathrm{T}}$} & Q1 & $-13.0 \%$ ** & $-5.2 \%$ * & $8.7 \%$ *夫 & $9.5 \%$ ** \\
\hline & Q2 & $-3.4 \%$ & $-1.4 \%$ & $2.0 \%$ & $2.7 \%$ \\
\hline & Q3 & $-8.7 \%$ ** & $1.5 \%$ & $9.5 \%$ ** & $-2.2 \%$ \\
\hline & Q4 & $-6.6 \%$ ** & $-1.9 \%$ & $5.3 \%$ ** & $3.2 \%$ \\
\hline \multirow[t]{4}{*}{$\mathrm{TE}_{\mathrm{SP} 500, \mathrm{~T}}$} & Q1 & $13.0 \%$ ** & $-11.5 \%$ ** & $-4.1 \%$ & $2.7 \% *$ \\
\hline & Q2 & $-5.8 \% *$ & $-4.3 \%$ & $1.7 \%$ & $8.4 \%^{\star *}$ \\
\hline & Q3 & $-6.6 \%$ ** & $-5.0 \% *$ & $0.9 \%$ & $10.6 \%$ ** \\
\hline & Q4 & $-3.1 \%{ }^{\star \star}$ & $-9.3 \% \%^{\star \star}$ & $-4.5 \%$ * & $17.0 \%^{* \star}$ \\
\hline
\end{tabular}


Table 5

Impact of prior performance on the choice of risk level (returns adjusted with the Carhart model)

The table shows the difference in transition probabilities between different measures of risk in $T$ and $T+1$ for funds with a performance in the highest quarter in $T$ and for funds with a performance in the lowest quarter in $T$. XXX denotes that the target (column) variable is the same variable as in the appropriate row. The table shows the results for returns adjusted with the Carhart model. * denotes a value statistically different from 0 on a 95\% level and ** on a 99\% level. Standard errors have been computed by bootstrapping.

The results in the table have been computed as follows. Top-performing funds are funds with a return in the fourth quartile in one calendar year, poor-performing funds are funds with a return in the first quartile in one calendar year. Both groups have different transition matrices for the risk level in the next year. In this table, we show the difference of element-by-element subtraction of the transition matrices. The transition matrix of poor-performing funds has been subtracted from the matrix of top-performing funds. Therefore, positive elements indicate that the transition probability for top-performing funds was higher than for poor-performing funds and vice-versa.

\begin{tabular}{|c|c|c|c|c|c|}
\hline \multirow[b]{2}{*}{ from } & \multirow[t]{2}{*}{ to } & \multicolumn{4}{|c|}{$\begin{array}{c}\mathrm{XXX}_{\mathrm{T+1}} \\
\text { Difference }\end{array}$} \\
\hline & & Q1 & Q2 & Q3 & Q4 \\
\hline \multirow[t]{4}{*}{$\mathrm{STD}_{\mathrm{T}}$} & Q1 & $7.0 \%$ & $1.6 \%$ & $-5.8 \%$ & $-2.8 \%$ *夫 \\
\hline & Q2 & $2.1 \%$ & $-3.8 \%$ & $2.6 \%$ & $-1.0 \%$ \\
\hline & Q3 & $1.0 \%$ & $1.7 \%$ & $-0.1 \%$ & $-2.6 \%$ \\
\hline & Q4 & $0.0 \%$ & $0.0 \%$ & $-1.2 \%$ & $1.4 \%$ \\
\hline \multirow[t]{4}{*}{$\mathrm{MRP}_{\mathrm{SP} 500, \mathrm{~T}}$} & Q1 & $-0.2 \%$ & $-2.1 \%$ & $4.0 \%^{*}$ & $-1.6 \%$ \\
\hline & Q2 & $-6.8 \%$ ** & $-3.7 \%$ & $7.6 \%$ ** & $2.8 \%$ \\
\hline & Q3 & $-3.9 \% *$ & $-7.5 \% \%^{\star \star}$ & $2.7 \%$ & $8.6 \% *$ \\
\hline & Q4 & $-2.3 \%$ ** & $-1.2 \%$ & $0.0 \%$ & $2.9 \%$ \\
\hline \multirow[t]{4}{*}{$\mathrm{HML}_{\mathrm{T}}$} & Q1 & $-3.4 \%$ & $-1.5 \%$ & $2.4 \%^{*}$ & $2.5 \%^{*}$ \\
\hline & Q2 & $-5.9 \%$ ** & $7.1 \% \%^{\star \star}$ & $2.1 \%$ & $-3.3 \%$ \\
\hline & Q3 & $-4.6 \%{ }^{*}$ & $2.4 \%$ & $0.4 \%$ & $1.7 \%$ \\
\hline & Q4 & $0.0 \%$ & $-0.3 \%$ & $0.0 \%$ & $-0.1 \%$ \\
\hline \multirow[t]{4}{*}{$\mathrm{SMB}_{\mathrm{T}}$} & Q1 & $15.5 \%$ ** & $1.4 \%$ & $-10.3 \%^{* \star}$ & $-6.6 \% \%^{* \star}$ \\
\hline & Q2 & $7.4 \%$ ** & $-0.3 \%$ & $-3.2 \%$ & $-3.7 \%^{*}$ \\
\hline & Q3 & $-3.9 \% *$ & $0.0 \%$ & $-0.1 \%$ & $4.1 \%$ \\
\hline & Q4 & $-0.5 \%$ & $-0.2 \%$ & $4.1 \% *$ & $-3.4 \%$ * \\
\hline \multirow[t]{4}{*}{$\mathrm{UMD}_{\mathrm{T}}$} & Q1 & $1.7 \%$ & $1.2 \%$ & $1.9 \%$ & $-4.9 \% \%^{* \star}$ \\
\hline & Q2 & $-2.0 \%$ & $8.1 \%$ ** & $-0.4 \%$ & $-5.5 \%$ ** \\
\hline & Q3 & $-7.2 \%$ *夫 & $0.6 \%$ & $11.2 \%$ ** & $-4.0 \%$ \\
\hline & Q4 & $-2.6 \% *$ & $-0.5 \%$ & $5.9 \%$ ** & $-2.6 \%$ \\
\hline \multirow[t]{4}{*}{$\mathrm{TE}_{\mathrm{SP} 500, \mathrm{~T}}$} & Q1 & $30.4 \%$ ** & $-6.9 \%^{\star \star}$ & $-18.9 \%^{\star \star}$ & $-4.4 \% \%^{* *}$ \\
\hline & Q2 & $3.6 \%$ & $3.6 \%$ & $-3.2 \%$ & $-4.0 \%$ \\
\hline & Q3 & $-1.8 \%$ * & $5.9 \% *$ & $-2.6 \%$ & $-1.4 \%$ \\
\hline & Q4 & $-0.1 \%$ & $0.0 \%$ & $1.6 \%$ & $-1.5 \%$ \\
\hline
\end{tabular}




\section{Table A1}

Impact of prior performance on the choice of risk level (returns adjusted with the S\&P 500)

The table shows the transition probabilities between different measures of risk in $T$ and $T+1$ for funds with a performance in the highest quarter in $T$ (first four columns), for funds with a performance in the lowest quarter in $T$ (middle four columns), and the difference between these transition probabilities. XXX denotes that the target (column) variable is the same variable as in the appropriate row. The table shows the results for returns adjusted with the S\&P 500. For the left and middle set of columns, * denotes a value statistically different from 0.25 on a $95 \%$ level and ** on a $99 \%$ level. For the difference between transition probabilities in the right set of columns, the null hypothesis is 0.00 , i.e., we test whether this difference is statistically different from 0 . Standard errors have been computed by bootstrapping.

\begin{tabular}{|c|c|c|c|c|c|c|c|c|c|c|c|c|c|}
\hline \multirow[b]{2}{*}{ from } & \multirow[t]{2}{*}{ to } & \multicolumn{4}{|c|}{$\begin{array}{c}X X X_{T+1} \\
R_{\text {SP500 }}=4 Q\end{array}$} & \multicolumn{4}{|c|}{$\begin{array}{c}X X X_{T+1} \\
R_{S P 500, T}=1 Q\end{array}$} & \multicolumn{4}{|c|}{$\begin{array}{c}\mathrm{XXX}_{\mathrm{T+1}} \\
\text { Difference }\end{array}$} \\
\hline & & Q1 & Q2 & Q3 & Q4 & Q1 & Q2 & Q3 & Q4 & Q1 & Q2 & Q3 & Q. \\
\hline \multirow{4}{*}{$\mathrm{STD}_{\mathrm{T}}$} & Q1 & $50.6 \%^{* \star}$ & $31.1 \%^{\star \star}$ & $15.5 \%^{*}$ & $2.7 \%^{*}$ & $44.2 \%^{\star \star}$ & $32.7 \%^{*}$ & $16.6 \% *$ & $6.3 \%^{*}$ & $6.3 \%$ & $-1.5 \%$ & $-1.1 \%$ & $-3.6^{6}$ \\
\hline & Q2 & $22.3 \%$ & $35.4 \%^{\star \star}$ & $29.8 \% *$ & $12.3 \%^{*}$ & $32.7 \%$ * & $36.3 \%^{\star \star}$ & $22.4 \%$ & $8.4 \% *$ & $-10.3 \%^{* \star}$ & $-0.9 \%$ & $7.4 \%^{*}$ & $3.8^{\prime}$ \\
\hline & Q3 & $4.8 \% \%^{*}$ & $16.1 \%^{*}$ & $39.5 \%^{\star \star}$ & $39.4 \%^{\star \star}$ & $13.4 \% *$ & $25.2 \%$ & $38.9 \%^{\star \star}$ & $22.3 \%$ & $-8.5 \%$ ** & $-9.0 \%^{* \star}$ & $0.0 \%$ & 17.0 \\
\hline & Q4 & $0.3 \% \%^{*}$ & $2.6 \%^{*}$ & $14.3 \%^{*}$ & $82.5 \%^{\star \star}$ & $2.5 \%^{*}$ & $8.6 \%^{*}$ & $25.1 \%$ & $63.6 \%^{\star \star}$ & $-2.1 \%^{\star *}$ & $-6.0 \%$ ** & $-10.7 \%^{* \star}$ & 18.9 \\
\hline \multirow[t]{4}{*}{$\mathrm{MRP}_{\mathrm{SP} 500, \mathrm{~T}}$} & Q1 & $54.3 \%^{* \star}$ & $23.8 \%$ & $14.8 \%^{*}$ & $6.9 \%^{*}$ & $40.9 \%^{\star \star}$ & $32.2 \%^{\star \star}$ & $16.7 \%^{*}$ & $10.0 \% *$ & $13.3 \%^{* \star}$ & $-8.4 \%^{\star \star}$ & $-1.8 \%$ & $-3.0^{\prime}$ \\
\hline & Q2 & $31.0 \%^{* \star}$ & $26.5 \%$ & $26.0 \%$ & $16.3 \%^{*}$ & $27.6 \%$ & $33.3 \%^{\star \star}$ & $22.6 \%$ & $16.3 \% *$ & $3.3 \%$ & $-6.8 \%^{\star \star}$ & $3.3 \%$ & 0.0 \\
\hline & Q3 & $13.8 \%{ }^{*}$ & $23.3 \%$ & $30.6 \%^{* \star}$ & $32.1 \%^{\star \star}$ & $19.6 \% *$ & $28.1 \%$ & $28.8 \%$ & $23.3 \%$ & $-5.8 \%^{* \star}$ & $-4.7 \%^{\star \star}$ & $1.7 \%$ & $8.8^{\circ}$ \\
\hline & Q4 & $3.9 \%^{*}$ & $11.3 \%$ * & $22.1 \%^{*}$ & $62.5 \%^{\star \star}$ & $8.9 \%^{*}$ & $13.2 \% *$ & $25.1 \%$ & $52.6 \% \%^{\star \star}$ & $-5.0 \%^{\star \star}$ & $-1.8 \%$ & $-3.0 \%$ & 9.80 \\
\hline \multirow[t]{4}{*}{$\mathrm{HML}_{\mathrm{T}}$} & Q1 & $46.1 \%^{* \star}$ & $21.6 \% *$ & $17.8 \%^{*}$ & $14.3 \%^{*}$ & $54.7 \%^{\star \star}$ & $25.2 \%$ & $12.4 \%^{*}$ & $7.5 \%^{*}$ & $-8.5 \%^{\star \star}$ & $-3.6 \%$ & $5.4 \%^{* \star}$ & $6.7^{\circ}$ \\
\hline & Q2 & $26.0 \%$ & $28.8 \%$ & $24.5 \%$ & $20.4 \%^{*}$ & $34.5 \%^{\star \star}$ & $29.4 \%^{\star \star}$ & $22.1 \% *$ & $13.8 \%{ }^{*}$ & $-8.4 \%^{\star *}$ & $-0.5 \%$ & $2.3 \%$ & 6.60 \\
\hline & Q3 & $14.3 \% *$ & $18.7 \%^{*}$ & $31.9 \%^{* \star}$ & $34.9 \%^{* \star}$ & $21.4 \%$ & $22.8 \%$ & $26.1 \%$ & $29.5 \%^{\star \star}$ & $-7.1 \%^{* *}$ & $-4.1 \%$ & $5.8 \%{ }^{*}$ & $5.4^{\prime}$ \\
\hline & Q4 & $7.7 \%^{\star}$ & $13.3 \%$ * & $26.2 \%$ & $52.5 \%^{\star \star}$ & $17.6 \%$ * & $13.9 \%$ * & $2.0 \%$ & $45.4 \%^{\star \star}$ & $-9.8 \%^{\star \star}$ & $-0.5 \%$ & $3.2 \%{ }^{*}$ & 7.10 \\
\hline \multirow[t]{4}{*}{$\mathrm{SMB}_{\mathrm{T}}$} & Q1 & $38.7 \%^{* \star}$ & $24.7 \%$ & $22.2 \%^{*}$ & $14.2 \%^{*}$ & $45.5 \%^{\star \star}$ & $27.9 \%$ & $19.2 \%^{*}$ & $7.3 \%^{*}$ & $-6.7 \%^{\star}$ & $-3.1 \%$ & $3.0 \%$ & $6.80^{\circ}$ \\
\hline & Q2 & $24.0 \%$ & $29.2 \%^{\star \star}$ & $25.3 \%$ & $21.3 \%^{*}$ & $35.5 \%^{\star \star}$ & $31.1 \%^{\star \star}$ & $19.7 \%^{*}$ & $13.6 \%{ }^{*}$ & $-11.4 \%^{* \star}$ & $-1.8 \%$ & $5.5 \%{ }^{*}$ & 7.79 \\
\hline & Q3 & $7.2 \%^{*}$ & $10.7 \%$ * & $36.0 \%^{\star \star}$ & $45.9 \%^{\star \star}$ & $20.3 \%$ * & $18.7 \%^{*}$ & $30.9 \%^{\star \star}$ & $29.9 \%^{\star \star}$ & $-13.1 \%^{\star \star}$ & $-7.9 \%$ ** & $5.0 \% *$ & 16.0 \\
\hline & Q4 & $0.8 \%^{*}$ & $2.3 \%^{*}$ & $19.1 \%^{*}$ & $77.6 \%^{\star \star}$ & $7.4 \%{ }^{*}$ & $8.1 \%^{*}$ & $20.4 \%$ * & $63.9 \%^{\star \star}$ & $-6.5 \%^{* \star}$ & $-5.8 \%^{* \star}$ & $-1.2 \%$ & 13.6 \\
\hline \multirow[t]{4}{*}{$\mathrm{UMD}_{\mathrm{T}}$} & Q1 & $33.2 \%$ ** & $17.6 \%{ }^{*}$ & $24.9 \%$ & $24.1 \%$ & $46.3 \%^{\star \star}$ & $22.8 \%{ }^{*}$ & $16.2 \%^{*}$ & $14.6 \%{ }^{*}$ & $-13.0 \%^{\star \star}$ & $-5.2 \%^{*}$ & $8.7 \%^{\star \star}$ & 9.50 \\
\hline & Q2 & $25.3 \%$ & $24.6 \%$ & $25.3 \%$ & $24.5 \%$ & $28.8 \%$ * & $26.1 \%$ & $23.1 \%$ & $21.8 \%{ }^{*}$ & $-3.4 \%$ & $-1.4 \%$ & $2.0 \%$ & 2.7 \\
\hline & Q3 & $13.3 \%{ }^{*}$ & $23.8 \%$ & $32.2 \%^{\star \star}$ & $30.6 \%^{\star \star}$ & $22.1 \%$ & $22.2 \%$ & $22.6 \%$ & $32.8 \%^{\star \star}$ & $-8.7 \%^{\star \star}$ & $1.5 \%$ & $9.5 \%$ ** & -2.2 \\
\hline & Q4 & $8.3 \%^{*}$ & $11.4 \%$ * & $25.1 \%$ & $55.0 \%^{\star \star}$ & $14.9 \%$ * & $13.3 \%$ * & $19.8 \% *$ & $51.8 \%^{\star \star}$ & $-6.6 \%^{\star \star}$ & $-1.9 \%$ & $5.3 \%$ ** & 3.2 \\
\hline \multirow[t]{4}{*}{$\mathrm{TE}_{\mathrm{SP} 500, \mathrm{~T}}$} & Q1 & $55.0 \%^{* \star}$ & $27.1 \%$ & $11.4 \%^{*}$ & $6.3 \%^{*}$ & $42.0 \%^{\star \star}$ & $38.7 \%^{\star \star}$ & $15.5 \%^{*}$ & $3.6 \%^{*}$ & $13.0 \%^{* \star}$ & $-11.5 \%^{\star \star}$ & $-4.1 \%$ & $2.7^{\prime}$ \\
\hline & Q2 & $13.1 \%$ * & $35.0 \%^{\star \star}$ & $27.3 \%$ & $24.3 \%$ & $19.0 \% *$ & $39.4 \%^{\star \star}$ & $25.0 \%$ & $15.8 \%{ }^{*}$ & $-5.8 \% *$ & $-4.3 \%$ & $1.7 \%$ & 8.40 \\
\hline & Q3 & $2.1 \%^{*}$ & $19.7 \%^{*}$ & $33.4 \%^{\star \star}$ & $44.5 \%^{\star \star}$ & $8.8 \%^{*}$ & $24.8 \%$ & $32.5 \%^{\star \star}$ & $33.8 \%^{\star \star}$ & $-6.6 \%^{\star \star}$ & $-5.0 \% *$ & $0.9 \%$ & 10.6 \\
\hline & Q4 & $0.3 \% \%^{*}$ & $4.7 \%^{*}$ & $20.8 \%$ * & $74.0 \%^{\star \star}$ & $3.5 \%^{*}$ & $14.0 \%$ * & $25.4 \%$ & $56.9 \%^{\star *}$ & $-3.1 \%^{\star *}$ & $-9.3 \%^{* *}$ & $-4.5 \%$ * & 17.0 \\
\hline
\end{tabular}


Table A2

Impact of prior performance on the choice of risk level (returns adjusted with the Carhart model)

The table shows the transition probabilities between different measures of risk in $T$ and $T+1$ for funds with a performance in the highest quarter in $T$ (first four columns), for funds with a performance in the lowest quarter in $T$ (middle four columns), and the difference between these transition probabilities. XXX denotes that the target (column) variable is the same variable as in the appropriate row. The table shows the results for returns adjusted with the Carhart model. For the left and middle set of columns, * denotes a value statistically different from 0.25 on a $95 \%$ level and ** on a $99 \%$ level. For the difference between transition probabilities in the right set of columns, the null hypothesis is 0.00, i.e., we test whether this difference is statistically different from 0 . Standard errors have been computed by bootstrapping.

\begin{tabular}{|c|c|c|c|c|c|c|c|c|c|c|c|c|c|}
\hline \multirow[b]{2}{*}{ from } & \multirow[t]{2}{*}{ to } & \multicolumn{4}{|c|}{$\begin{array}{c}\mathrm{XXX}_{\mathrm{T}+1} \\
\mathrm{R}_{\text {Carhart } \mathrm{T}}=4 \mathrm{Q}\end{array}$} & \multicolumn{4}{|c|}{$\begin{array}{c}\mathrm{XXX} \mathrm{X}_{\mathrm{T}+1} \\
\mathrm{R}_{\text {Carhart } \mathrm{T}}=1 \mathrm{Q}\end{array}$} & \multicolumn{4}{|c|}{$\begin{array}{c}\mathrm{XXX}_{\mathrm{T+1}} \\
\text { Difference }\end{array}$} \\
\hline & & Q1 & Q2 & Q3 & Q4 & Q1 & Q2 & Q3 & Q4 & Q1 & Q2 & Q3 & Q4 \\
\hline \multirow[t]{4}{*}{$\mathrm{STD}_{\mathrm{T}}$} & Q1 & $47.3 \%^{* *}$ & $32.2 \% *$ & $17.5 \%$ * & $2.9 \%^{*}$ & $40.2 \%^{\star \star}$ & $30.5 \% *$ & $23.4 \%$ & $5.8 \%^{*}$ & $7.0 \%$ & $1.6 \%$ & $-5.8 \%$ & $-2.8 \%^{\circ}$ \\
\hline & Q2 & $23.6 \%$ & $32.5 \%^{\star *}$ & $33.4 \%^{* *}$ & $10.4 \%$ * & $21.4 \%$ & $36.3 \%^{* \star}$ & $30.7 \%$ * & $11.4 \%$ * & $2.1 \%$ & $-3.8 \%$ & $2.6 \%$ & $-1.0 \%$ \\
\hline & Q3 & $8.1 \%^{*}$ & $22.2 \%$ & $38.4 \%^{\star *}$ & $31.1 \%^{\star \star}$ & $7.0 \%{ }^{*}$ & $20.5 \% *$ & $38.5 \%^{* \star}$ & $33.8 \%^{\star \star}$ & $1.0 \%$ & $1.7 \%$ & $-0.1 \%$ & $-2.6 \%$ \\
\hline & Q4 & $1.3 \%^{*}$ & $6.4 \% \%^{*}$ & $20.7 \%$ * & $71.5 \%^{\star \star}$ & $1.5 \%^{*}$ & $6.4 \%^{*}$ & $21.9 \% *$ & $70.0 \%^{* \star}$ & $0.0 \%$ & $0.0 \%$ & $-1.2 \%$ & $1.4 \%$ \\
\hline \multirow[t]{4}{*}{$\mathrm{MRP}_{\mathrm{SP} 500, \mathrm{~T}}$} & Q1 & $42.3 \%^{* \star}$ & $26.8 \%$ & $21.1 \%^{*}$ & $9.5 \%^{*}$ & $42.6 \%^{* \star}$ & $29.0 \% *$ & $17.0 \%{ }^{*}$ & $11.2 \%{ }^{*}$ & $-0.2 \%$ & $-2.1 \%$ & $4.0 \%^{*}$ & $-1.6 \%$ \\
\hline & Q2 & $19.0 \% *$ & $28.2 \%$ & $31.3 \%^{\star *}$ & $21.3 \%$ & $25.8 \%$ & $31.9 \%^{\star \star}$ & $23.6 \%$ & $18.5 \%$ * & $-6.8 \%^{\star \star}$ & $-3.7 \%$ & $7.6 \% \%^{\star \star}$ & $2.8 \%$ \\
\hline & Q3 & $12.0 \% *$ & $20.5 \% *$ & $32.9 \%^{\star \star}$ & $34.5 \%^{\star \star}$ & $15.9 \% *$ & $28.0 \%$ & $30.1 \%^{* \star}$ & $25.8 \%$ & $-3.9 \%^{*}$ & $-7.5 \%^{\star \star}$ & $2.7 \%$ & $8.6 \%$ \\
\hline & Q4 & $4.8 \% \%^{*}$ & $12.3 \%$ * & $23.4 \%$ & $59.3 \% \%^{\star \star}$ & $7.1 \%{ }^{*}$ & $13.5 \%$ * & $22.8 \%$ & $56.4 \%^{\star \star}$ & $-2.3 \%^{* \star}$ & $-1.2 \%$ & $0.0 \%$ & $2.9 \%$ \\
\hline \multirow[t]{4}{*}{$\mathrm{HML}_{\mathrm{T}}$} & Q1 & $50.9 \%^{\star \star}$ & $24.1 \%$ & $14.4 \% *$ & $10.4 \% *$ & $54.3 \%^{\star \star}$ & $25.6 \%$ & $12.0 \%$ * & $7.9 \%^{*}$ & $-3.4 \%$ & $-1.5 \%$ & $2.4 \%^{*}$ & $2.5 \%$ \\
\hline & Q2 & $29.1 \% *$ & $32.9 \%^{\star \star}$ & $24.6 \%$ & $13.2 \% *$ & $35.0 \%^{\star \star}$ & $25.8 \%$ & $22.4 \%^{*}$ & $16.5 \%$ * & $-5.9 \%^{\star \star}$ & $7.1 \%^{\star \star}$ & $2.1 \%$ & $-3.3 \%$ \\
\hline & Q3 & $16.4 \% *$ & $25.1 \%$ & $31.4 \%^{\star \star}$ & $26.9 \%$ & $21.0 \%$ & $22.7 \%$ & $30.9 \%^{* \star}$ & $25.1 \%$ & $-4.6 \%{ }^{*}$ & $2.4 \%$ & $0.4 \%$ & $1.7 \%$ \\
\hline & Q4 & $16.2 \%$ * & $14.8 \%$ * & $26.0 \%$ & $42.8 \%^{\star \star}$ & $16.1 \%^{*}$ & $15.1 \%$ * & $25.5 \%$ & $43.0 \%^{\star \star}$ & $0.0 \%$ & $-0.3 \%$ & $0.0 \%$ & $-0.1 \%$ \\
\hline \multirow[t]{4}{*}{$\mathrm{SMB}_{\mathrm{T}}$} & Q1 & $55.9 \%^{\star \star}$ & $26.4 \%$ & $11.1 \%{ }^{*}$ & $6.4 \%^{*}$ & $40.3 \%^{\star \star}$ & $24.9 \%$ & $21.5 \%{ }^{*}$ & $13.1 \%^{*}$ & $15.5 \%^{\star \star}$ & $1.4 \%$ & $-10.3 \% \%^{\star \star}$ & $-6.6 \%$ \\
\hline & Q2 & $37.3 \%^{\star \star}$ & $29.9 \%^{\star \star}$ & $19.3 \% *$ & $13.3 \%$ * & $29.9 \%^{\star \star}$ & $30.3 \%^{\star \star}$ & $22.5 \%$ & $17.1 \%^{*}$ & $7.4 \% \%^{\star \star}$ & $-0.3 \%$ & $-3.2 \%$ & $-3.7 \%$ \\
\hline & Q3 & $10.6 \% *$ & $14.8 \%{ }^{*}$ & $34.2 \%^{\star \star}$ & $40.2 \%^{\star *}$ & $14.6 \%{ }^{*}$ & $14.8 \%{ }^{*}$ & $34.4 \%^{\star \star}$ & $36.0 \%^{\star \star}$ & $-3.9 \% *$ & $0.0 \%$ & $-0.1 \%$ & $4.1 \%$ \\
\hline & Q4 & $4.1 \%^{*}$ & $6.0 \%^{*}$ & $23.4 \%$ & $66.3 \%^{* \star}$ & $4.6 \% \%^{*}$ & $6.2 \%{ }^{*}$ & $19.2 \%^{*}$ & $69.8 \%^{* \star}$ & $-0.5 \%$ & $-0.2 \%$ & $4.1 \% \%^{*}$ & $-3.4 \%$ \\
\hline \multirow[t]{4}{*}{$\mathrm{UMD}_{\mathrm{T}}$} & Q1 & $46.4 \%^{\star \star}$ & $22.4 \%$ & $17.8 \%{ }^{*}$ & $13.2 \%{ }^{*}$ & $44.6 \%^{\star \star}$ & $21.2 \% *$ & $15.9 \% *$ & $18.1 \%^{*}$ & $1.7 \%$ & $1.2 \%$ & $1.9 \%$ & $-4.9 \%$ \\
\hline & Q2 & $26.5 \%$ & $35.0 \%^{\star \star}$ & $22.4 \%$ & $15.9 \%$ * & $28.7 \%$ & $26.9 \%$ & $22.8 \%$ & $21.5 \%$ * & $-2.0 \%$ & $8.1 \%$ ** & $-0.4 \%$ & $-5.5 \%$ \\
\hline & Q3 & $16.1 \%$ * & $25.3 \%$ & $32.9 \%^{\star \star}$ & $25.5 \%$ & $23.3 \%$ & $24.7 \%$ & $21.6 \%$ & $30.2 \%{ }^{*}$ & $-7.2 \%^{\star \star}$ & $0.6 \%$ & $11.2 \%^{\star \star}$ & $-4.0 \%$ \\
\hline & Q4 & $12.7 \%$ * & $14.3 \%$ * & $27.8 \% \%^{*}$ & $45.0 \%^{\star \star}$ & $15.3 \%{ }^{*}$ & $14.9 \%$ * & $21.9 \%$ * & $47.7 \%^{\star \star}$ & $-2.6 \%{ }^{*}$ & $-0.5 \%$ & $5.9 \%^{\star \star}$ & $-2.6 \%$ \\
\hline \multirow[t]{4}{*}{$\mathrm{TE}_{\mathrm{SP} 500, \mathrm{~T}}$} & Q1 & $67.1 \%^{\star \star}$ & $24.0 \%$ & $5.3 \% *$ & $3.4 \%^{*}$ & $36.7 \%^{\star \star}$ & $31.0 \%{ }^{*}$ & $24.3 \%$ & $7.9 \%^{*}$ & $30.4 \%^{\star \star}$ & $-6.9 \%^{\star \star}$ & $-18.9 \%$ ** & $-4.4 \%$ \\
\hline & Q2 & $18.7 \%$ * & $37.8 \%^{\star \star}$ & $25.5 \%$ & $17.8 \%$ * & $15.0 \%{ }^{*}$ & $34.2 \%^{\star \star}$ & $28.8 \%$ & $21.9 \%$ & $3.6 \%$ & $3.6 \%$ & $-3.2 \%$ & $-4.0 \%$ \\
\hline & Q3 & $4.2 \%^{*}$ & $24.9 \%$ & $31.9 \%^{\star \star}$ & $38.7 \%^{\star \star}$ & $6.1 \%^{*}$ & $19.0 \% *$ & $34.6 \% \%^{\star \star}$ & $40.2 \%^{\star \star}$ & $-1.8 \% *$ & $5.9 \%{ }^{*}$ & $-2.6 \%$ & $-1.4 \%$ \\
\hline & Q4 & $1.6 \%{ }^{*}$ & $10.0 \% *$ & $26.7 \%$ & $61.5 \%^{* \star}$ & $1.8 \%{ }^{*}$ & $9.9 \%{ }^{*}$ & $25.1 \%$ & $63.0 \%^{\star \star}$ & $-0.1 \%$ & $0.0 \%$ & $1.6 \%$ & $-1.5 \%$ \\
\hline
\end{tabular}


